\title{
Evaluation of Intergroup Dialogue: A Review of the Empirical Literature
}

ADRIENNE DESSEL

MARY E. ROGGE

Practitioners in the developing field of intergroup dialogue seek to address critical social issues of prejudice and intergroup conflict. Goals of dialogue work include relationship building, civic participation, and social change. Outcome evaluation of this work is necessary to further understand the processes and effectiveness of dialogue practices, improve on the work being done, and obtain funding. This literature review summarizes empirical evaluation research in the field of intergroup dialogue and presents a compendium table. Strengths and limitations of current research are discussed, with emphasis on the importance of expanding evaluation work in this field.

Tntergroup conflict tears at the fabric of society in numerous ways. Whether based in prejudice, social identity, emotions, ideology, values, communication styles, or resources, human beings tend to be attached to their beliefs, categorize and stereotype others into "outgroups," and dominate others in a way that often leads to violence (Collier and Sambanis, 2002; Dovidio, 2001; LeBaron and Carstarphen, 1997; Lowry and Littlejohn, 2006; Maiese, 2006; Maoz, 2001; Spears, 2000; Staub, 2007; Weiner, 1998). Although aggression and interethnic conflict are assumed to be natural inclinations of human nature, the desire for harmony and peace balances these tendencies (Hamburg, 1998). The field of conflict resolution has arisen in response to this aspiration. Professionals involved in the field have a promising tool in intergroup dialogue, one that is at their disposal to be used to address the aforementioned 
societal rifts. This method requires more attention and evaluation as to its potential.

Dialogue as a process of human interaction and conflict resolution is an age-old yet still-evolving practice. An early form of dialogue was the Socratic method of sustained questioning and engaging participants in formulating their own theories about how the world works. Socrates' student Plato wrote "dialogues" that, although situated within a rhetorical tradition of using language to persuade, have been reinterpreted as techniques applied to situations of inequality and conflict (Zappen, 1996). Plato's dialogues initiated a practice whereby people determined their own answers to questions of concern while engaging in creation of shared meaning and understanding.

The contemporary practice of intergroup dialogue has a wide purview, ranging from academic to global arenas (Nagda, Kim, and Truelove, 2004; Pruitt and Kaufer, 2004). Nagda and colleagues are currently engaged in a multiuniversity study examining the outcomes of race and gender intergroup dialogues for student populations (Nagda, Gurin, and Zuniga, 2008). The United Nations Democratic Dialogue Project is bringing together ethnic groups steeped in long-standing conflict who are beginning to see each other as individuals (UNDP, 2008). With increased attention being paid to the practice of dialogue, questions should be raised about what effect this approach has on participants and whether and how dialogue achieves desired goals. Practitioners and researchers in the developing field of intergroup dialogue have produced an important body of literature and, more recently, have begun to evaluate the outcomes of such work (Gurin, Peng, Lopez, and Nagda, 1999; Hurtado, 2005; McCoy and McCormick, 2001; Nagda, 2006; Nagda, Kim, and Truelove, 2004; Nagda and Zuniga, 2003; Zuniga, Nagda, Chesler, and Cytron-Walker, 2007). In community, organizational, and interethnic settings, however, use of dialogue techniques has far outpaced any systematic efforts to measure the results of dialogue interaction. Further rigorous evaluation of intergroup dialogue is critical to understand the processes and outcomes involved in dialogue and to improve on the work (Dessel, Rogge, and Garlington, 2006; Hurtado, 2001; Khuri, 2004a; Nagda and Derr, 2004; Pruitt and Kaufer, 2004; Schoem and Hurtado, 2001; Stephan and Stephan, 2001).

Attending to outcomes creates varied reactions and sometimes resistance within the practitioner community. As McCoy and McCormick (2001) pointed out, evaluation of practices or programs calls into explicit and observable question how success can be defined and determined. There is 
an ongoing debate among dialogue researchers and practitioners as well about the value of assessing process or product in dialogue and the degree to which reality can be objectively measured (Abelson and others, 2003; WSP/UNDP-DRLAC, 2003). It is also important to recognize that incorporating outcome research into community-based dialogue practice can be time-consuming and expensive and is not often supported by funding.

However, outcome evaluation is a necessary component of dialogue practice to assess its effectiveness, improve on outcomes, and obtain financial support. Practitioners and academicians interested in understanding dialogic processes and outcomes face a number of challenges that are discussed in this article. Evaluators of intergroup dialogue must first define indicator variables of successful process and outcomes. Research methods and designs must be developed to measure these variables. Outcome measurement tools and program evaluation methods are important pieces of the puzzle as to whether and how dialogue may foster interpersonal and social change. A compendium of dialogue evaluation methods and tools will increase the potential to replicate and improve on current research knowledge (Rubin and Babbie, 2005). Such improvements will strengthen and promote intergroup dialogue in various public settings.

This article reviews the empirical literature on intergroup dialogue outcomes. First, we offer a definition of intergroup dialogue work as it is conducted in academic, community, and international venues. Next, we discuss the theoretical underpinnings of intergroup dialogue work. Then we review existing studies located between the years 1997 and 2006. We discuss summaries of design, methodology, sample, research questions, data collection tools, variables, and outcomes. A compendium table for comparison of studies is provided (Table 1). Conclusions from this literature review inform future directions for evaluation of intergroup dialogue.

\section{Intergroup Dialogue Defined}

As previously noted, intergroup dialogue has its roots in Western culture and the attempt to revive ancient conversational patterns and bridge the gap between individual and collective consciousness (Bohm, 1996; Slotte, 2006). Intergroup dialogue is a facilitated group experience that may occur once or may be sustained over time and is designed to give individuals and groups a safe and structured opportunity to explore attitudes about polarizing societal issues. Participants are encouraged to suspend assumptions, 


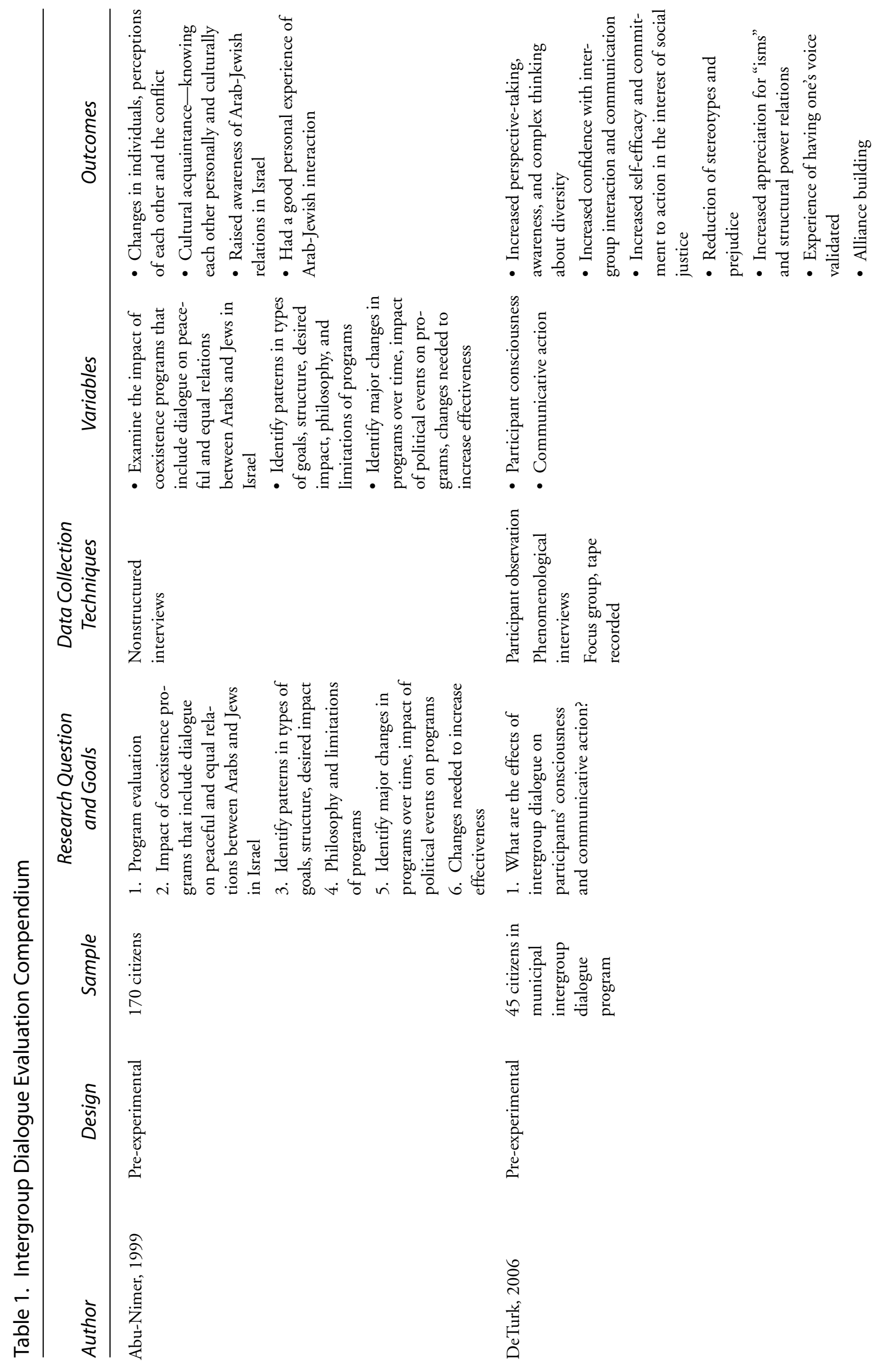




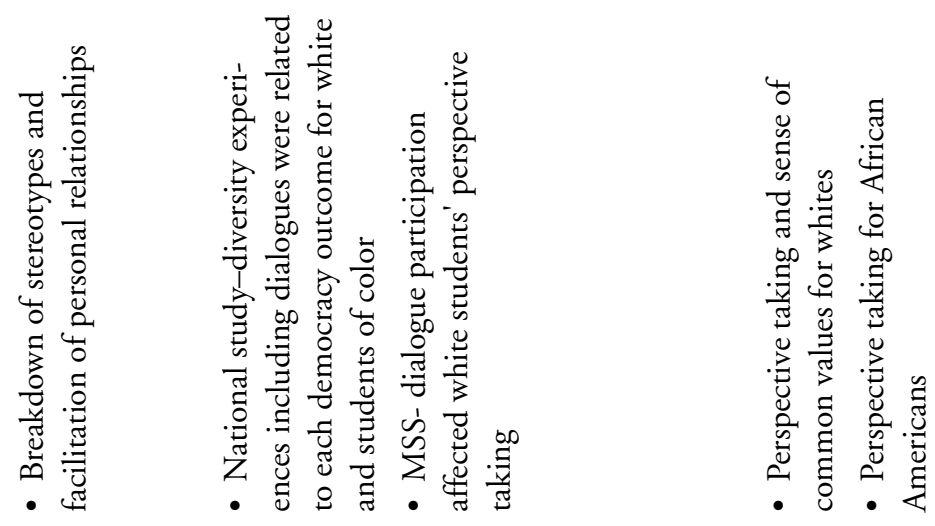

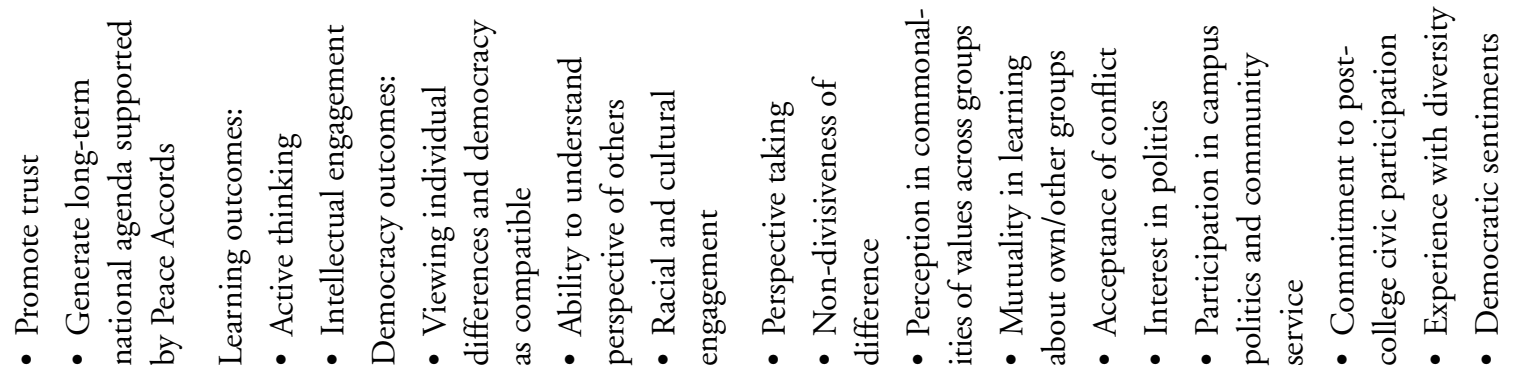
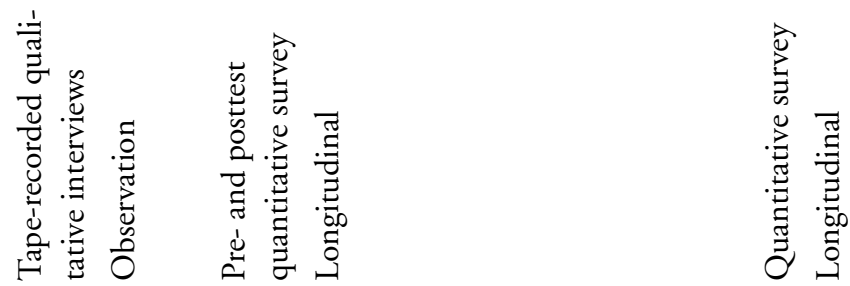

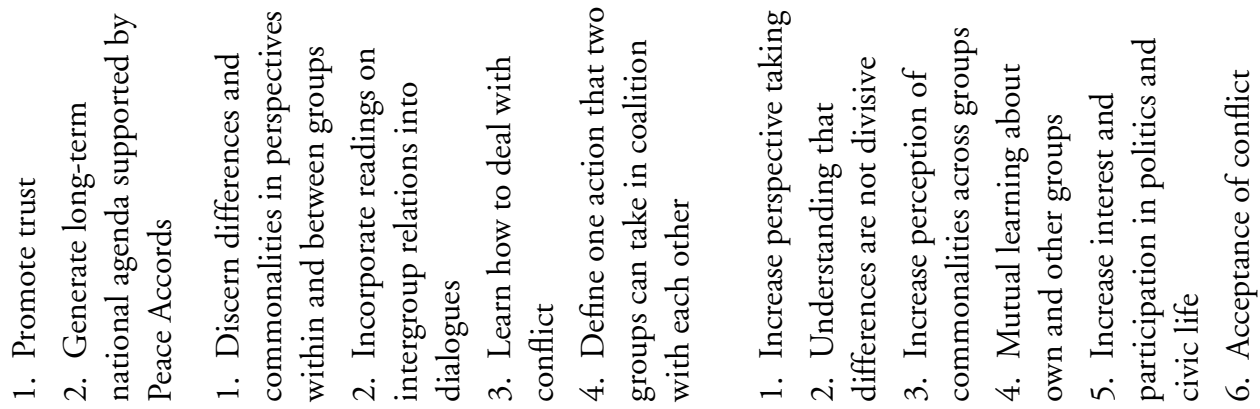

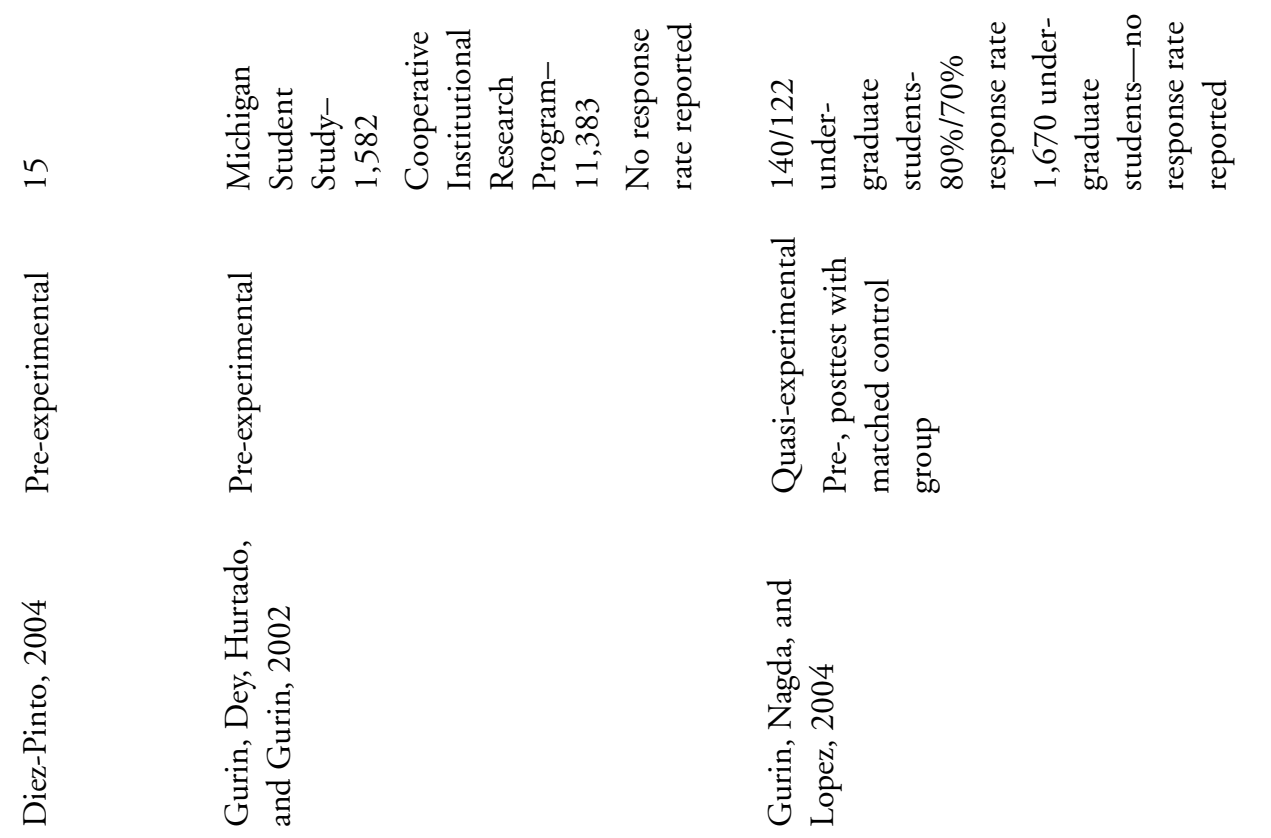




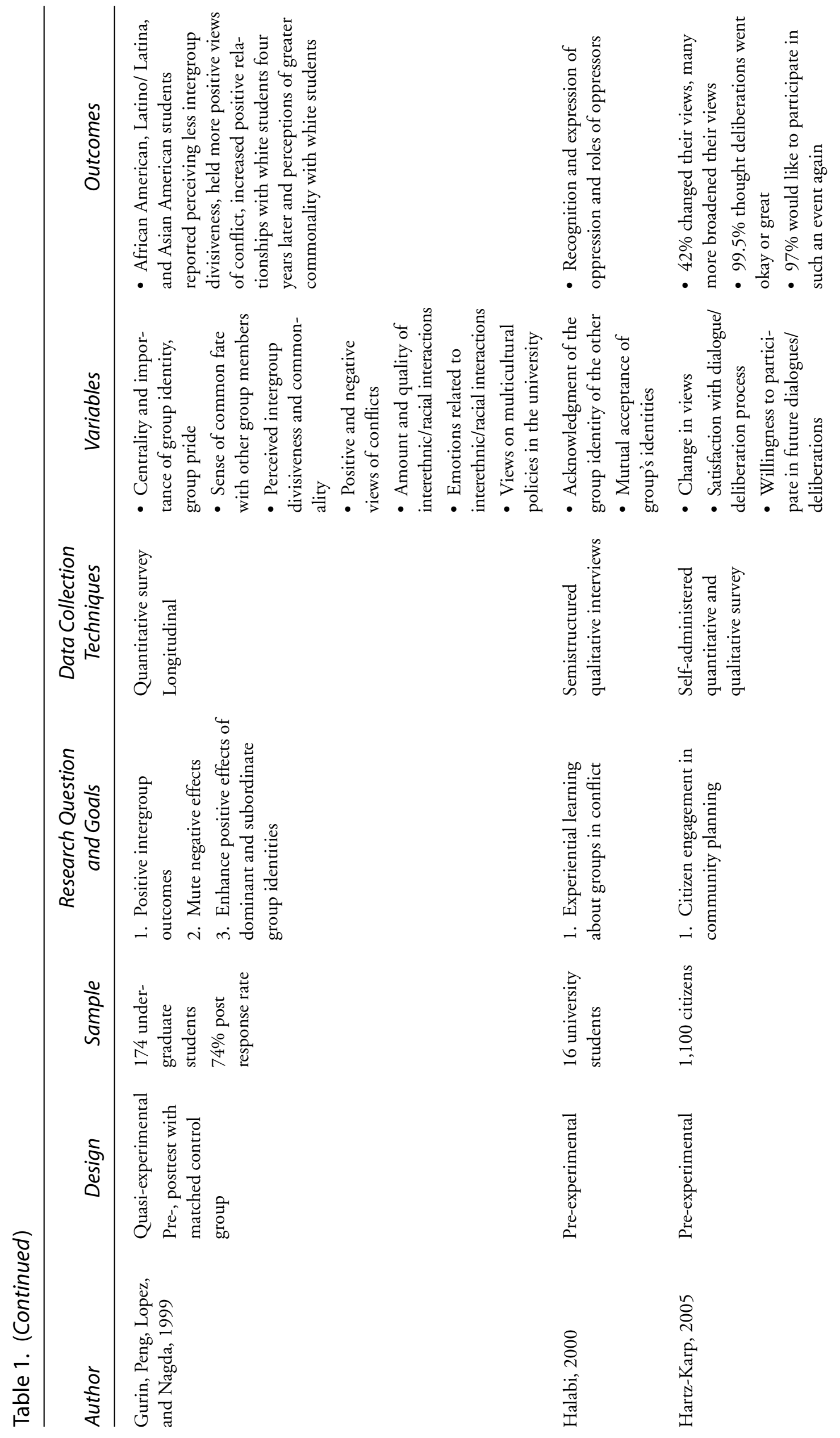



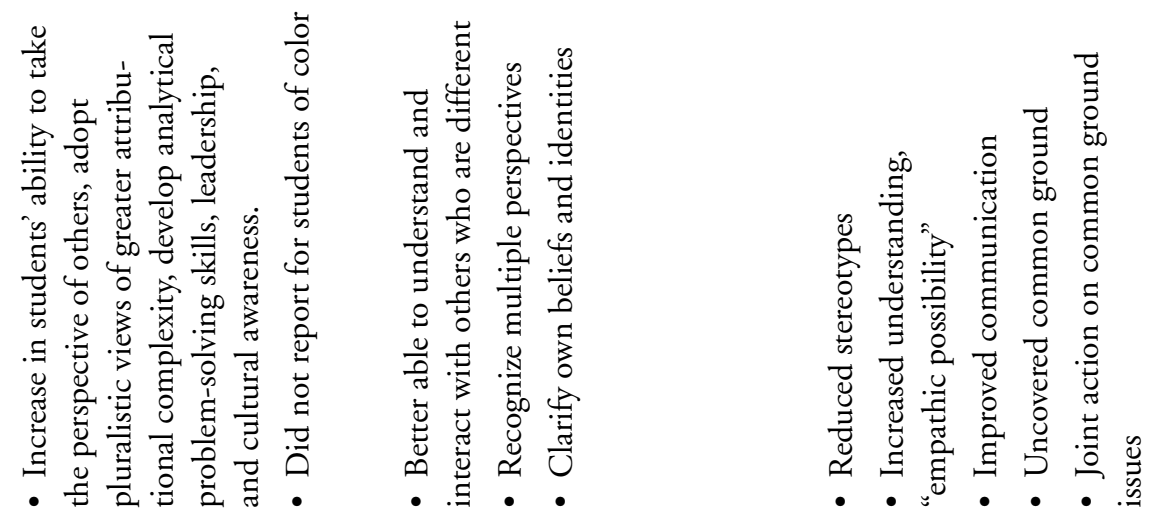

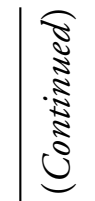
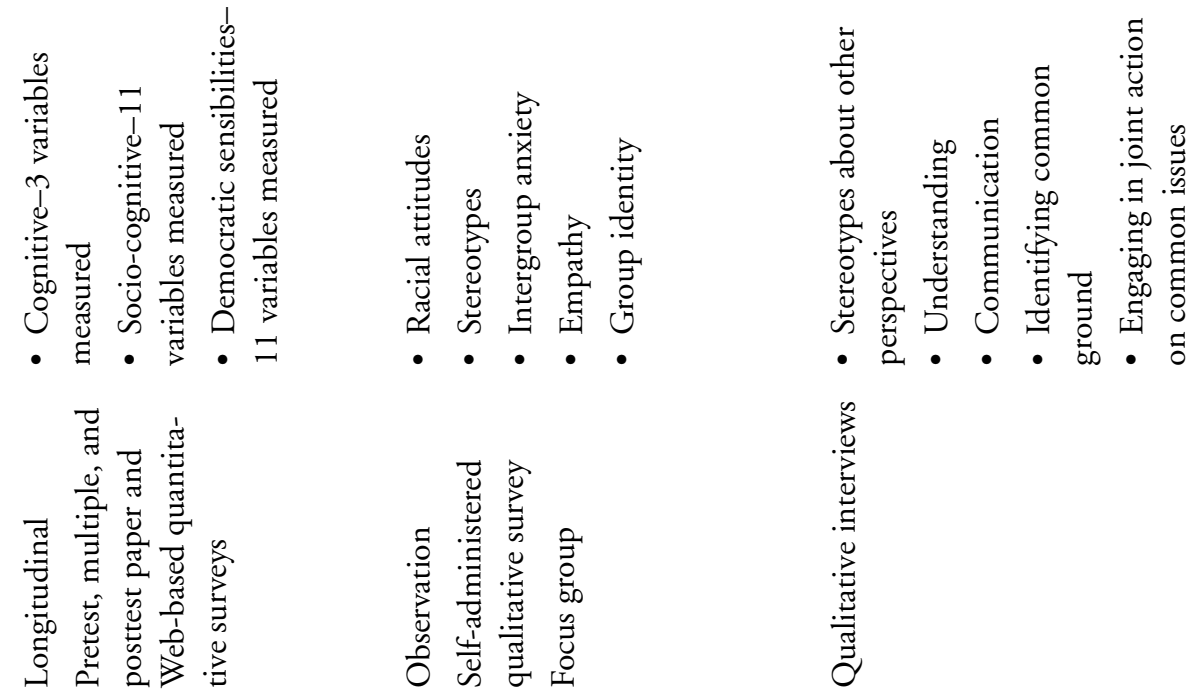

䓠
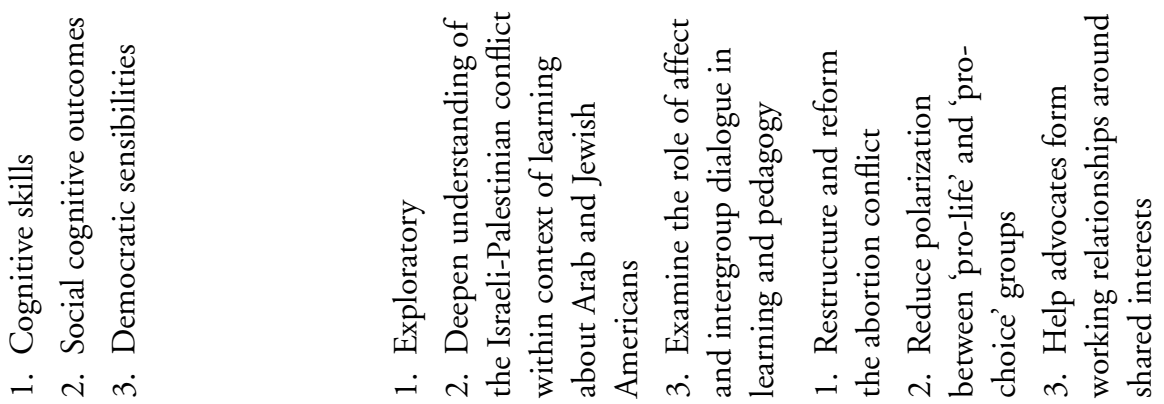

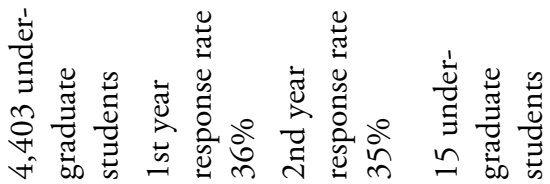

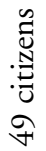

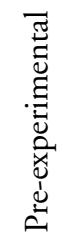

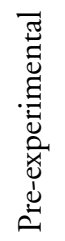

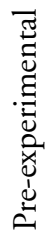

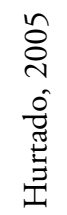

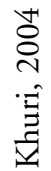

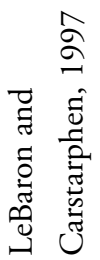




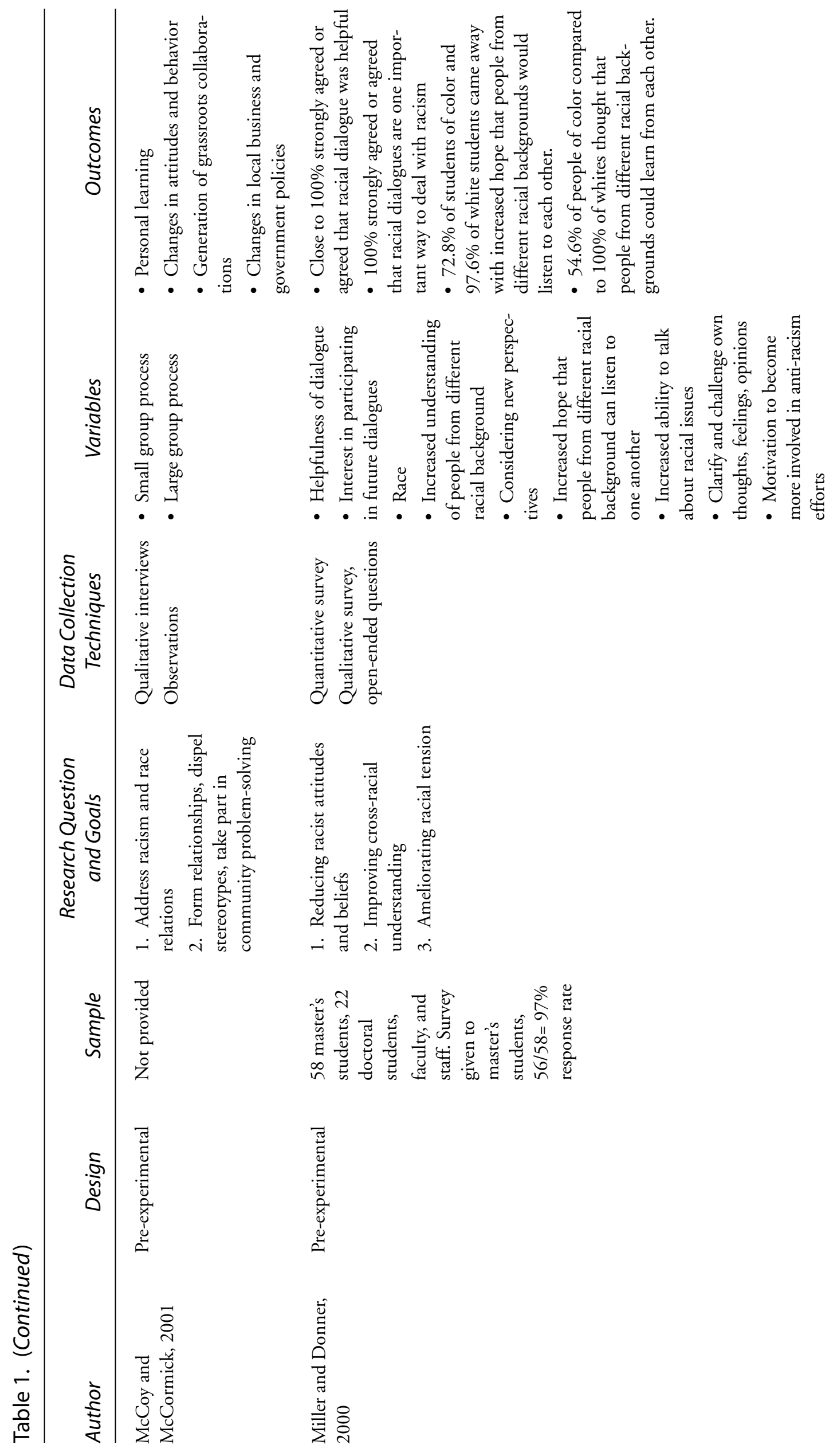



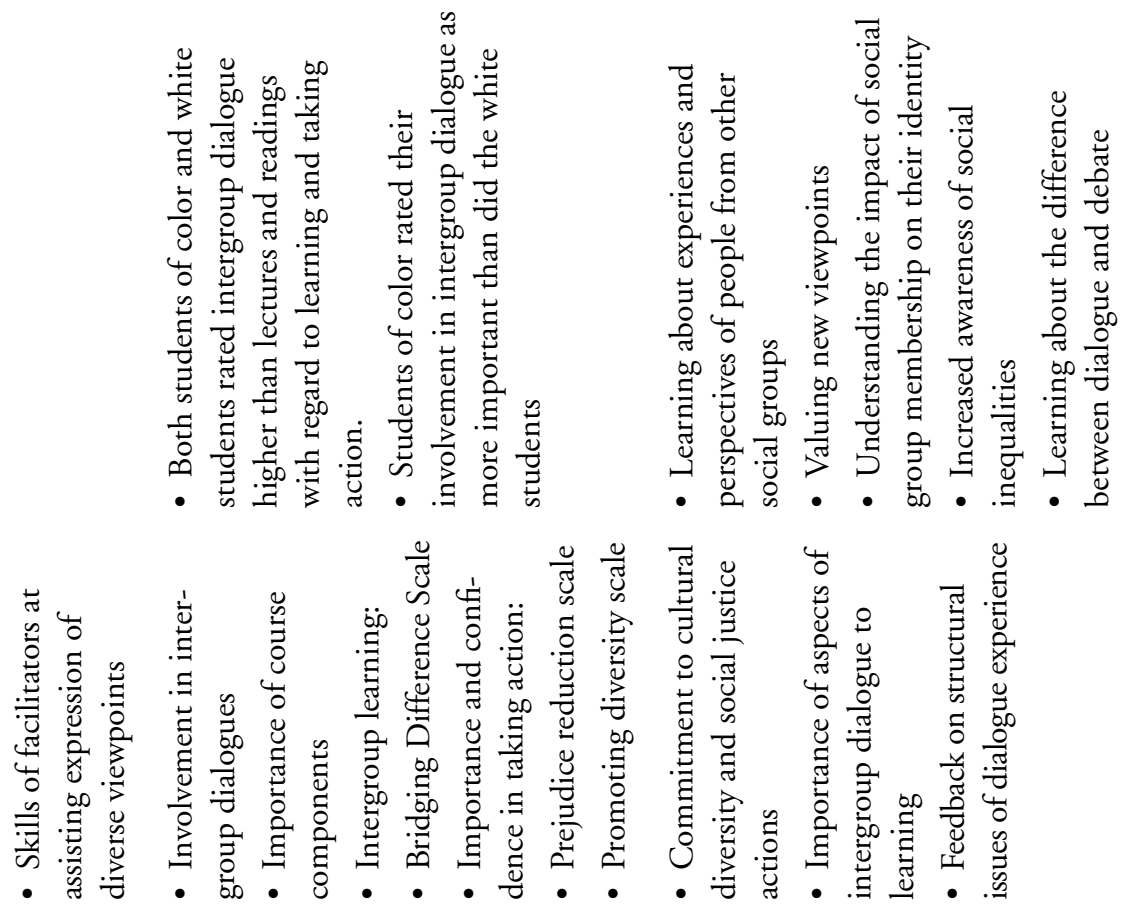

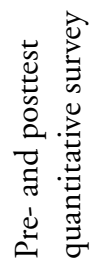

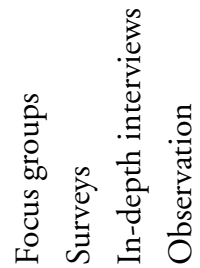
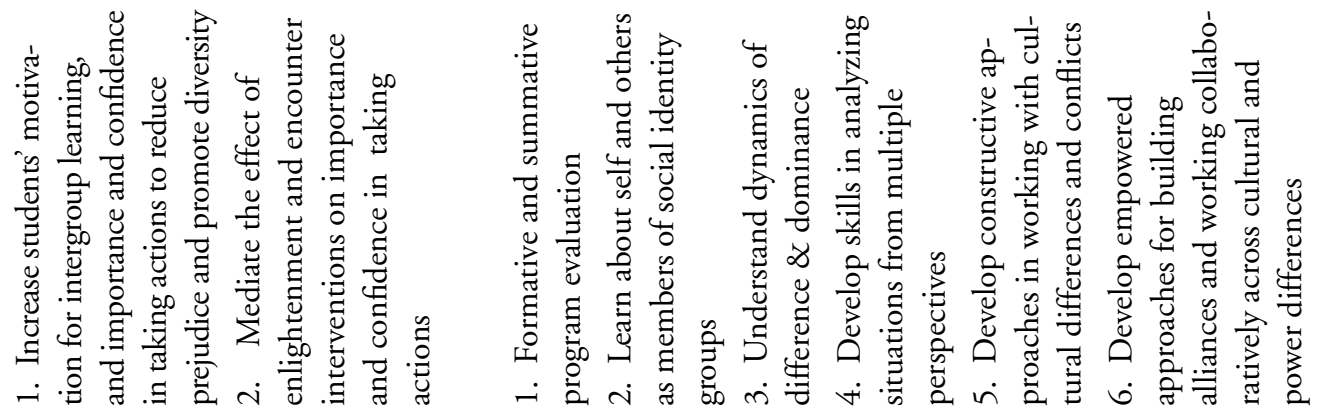

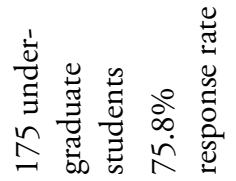

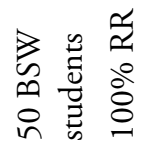

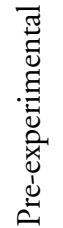

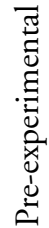

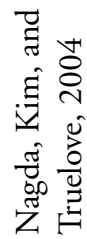

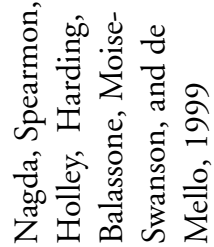




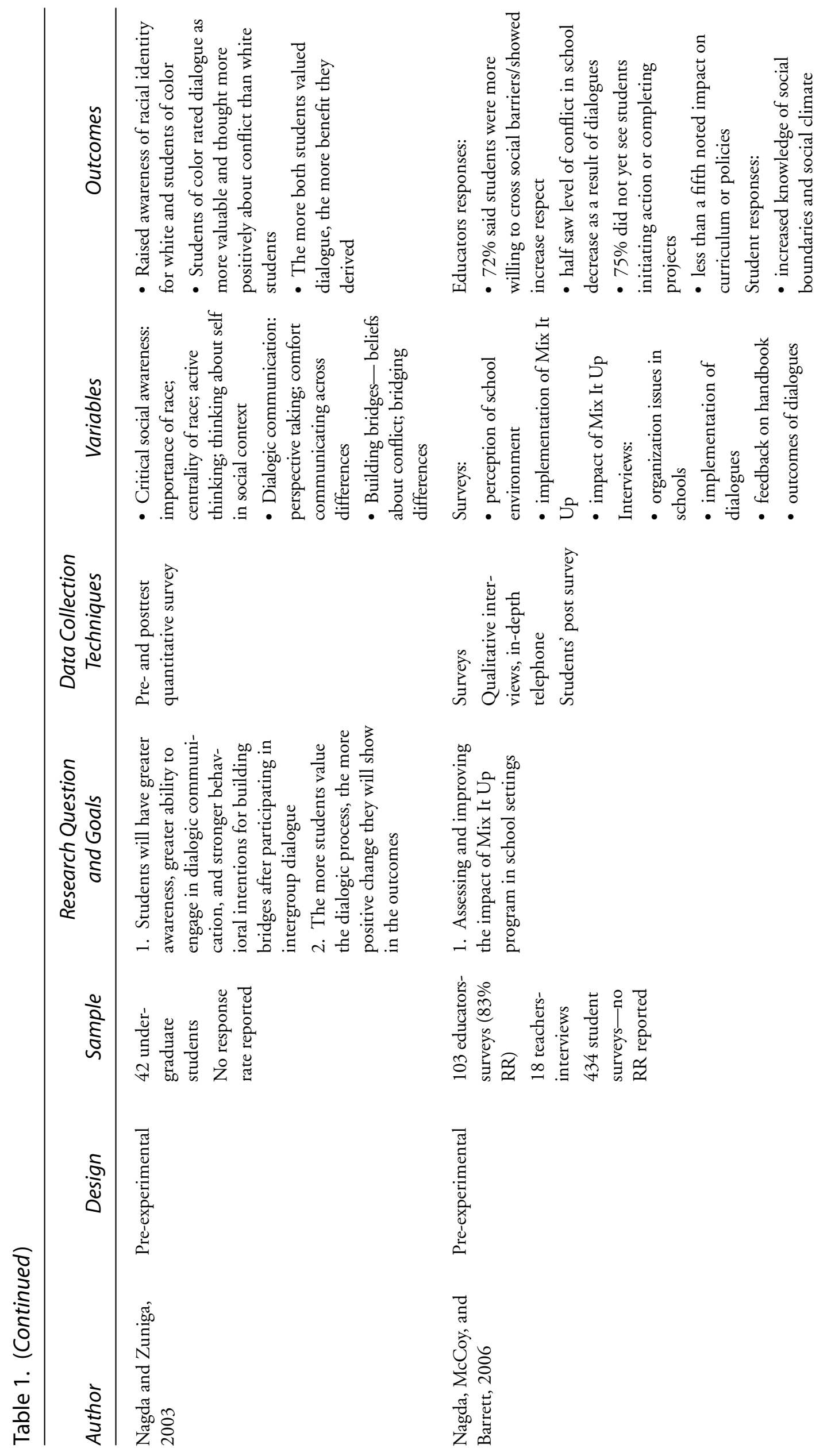



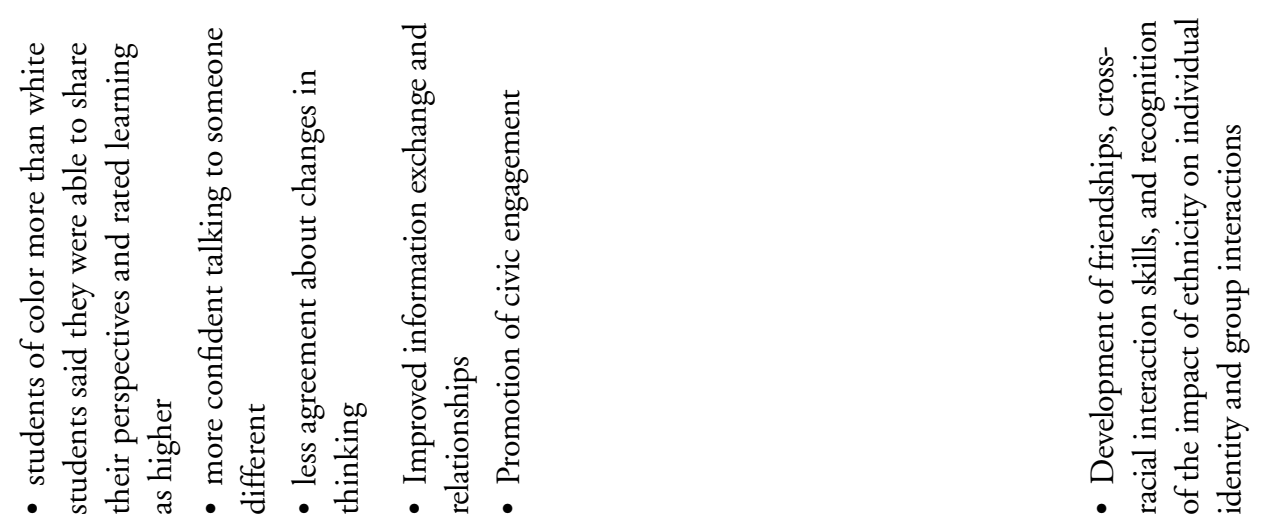

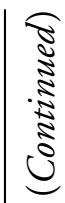
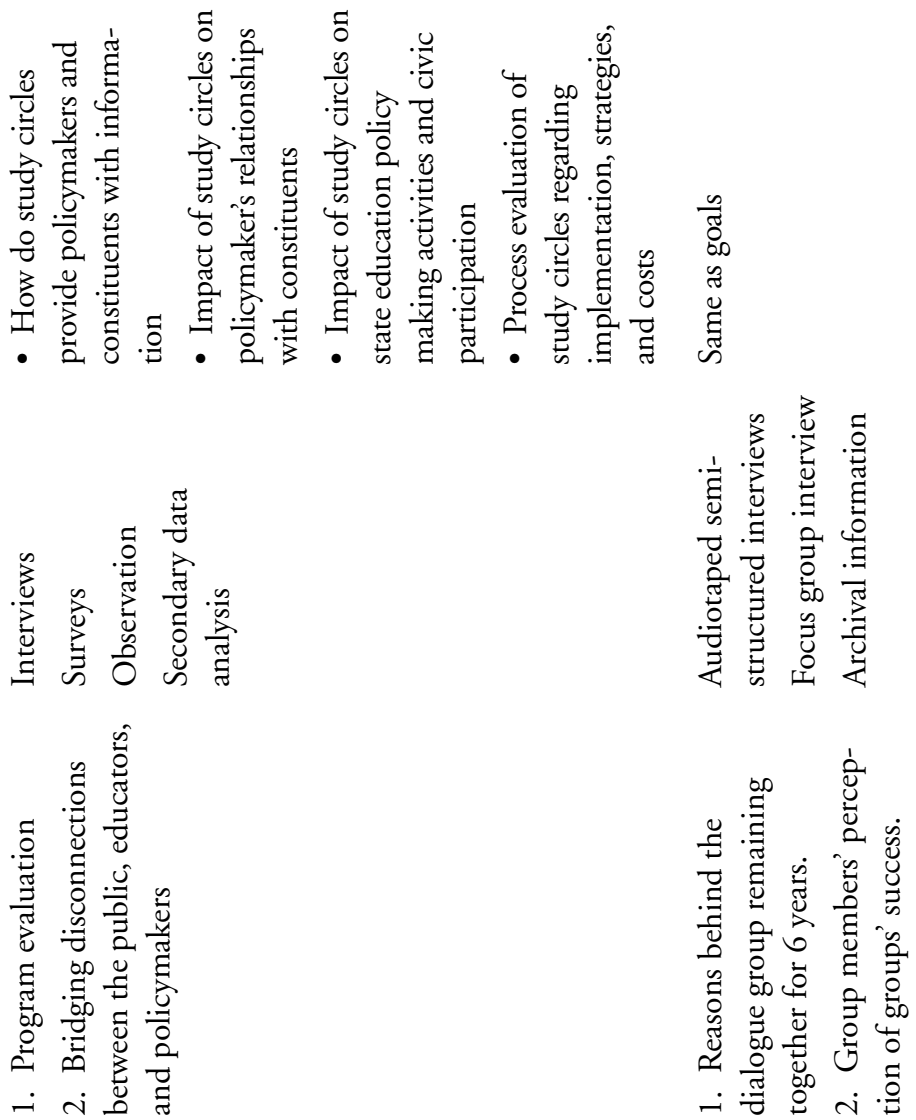

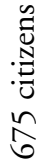

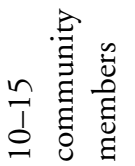

폼

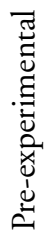

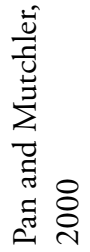

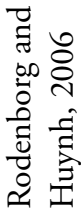




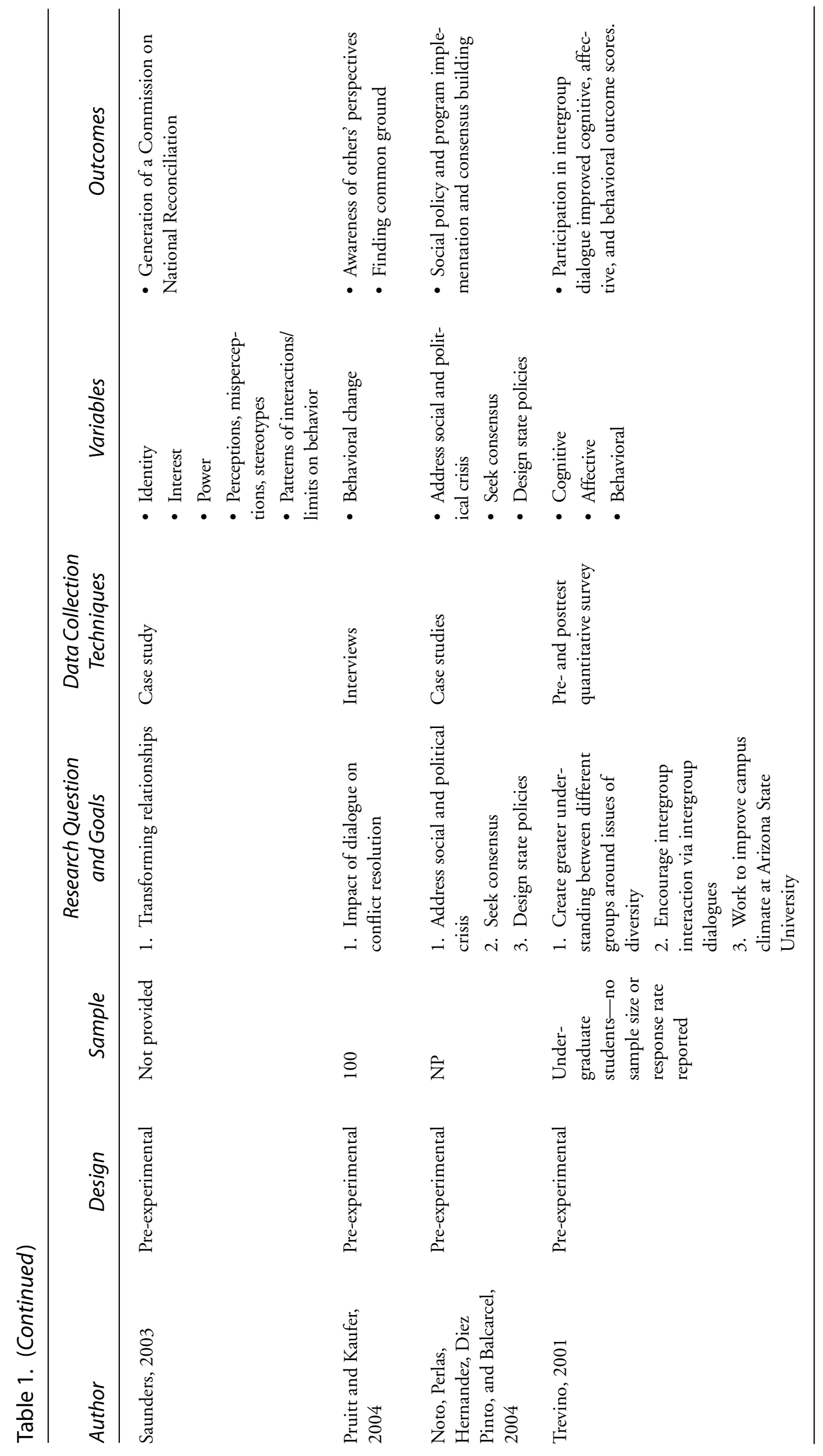


collaborate willingly, believe in the authenticity of all participants, speak from experience, and be open to possibilities (Cissna and Anderson, 2002; Dessel, Rogge, and Garlington, 2006; Isaacs, 1999). Characteristics of intergroup dialogue include fostering an environment that enables participants to speak and listen in the present while understanding the contributions of the past and the unfolding of the future (Dessel, Rogge, and Garlington, 2006). This type of environment is created by factors such as the choice of location for the dialogue, establishment of communication and relationships with dialogue participants, subject matter of dialogues, and knowledgeable design and facilitation of dialogue.

Intergroup dialogues may incorporate learning or experiential material and engage participants in "listening and being listened to with care ... speaking and being spoken to in a respectful manner ... sharing air time ... learning about the perspectives of others [and] reflecting on one's own views (Herzig and Chasin, 2006, p. 138). Such dialogue involves processes of appreciation of difference, critical self-reflection, and alliance building (Nagda, 2006). Dialogues are often cofacilitated by trained facilitators who may represent the social or cultural identities of the groups involved (Halabi, 2000; Nagda, 2006).

Dialogue as a method has been compared and contrasted to numerous other practices that seek to facilitate relationships and resolve conflict. Dialogue is differentiated from debate, which involves taking positions and challenging others, and from group therapy processes, which focus more on an individual's internal personal dynamics. Dialogue is dissimilar to mediation, which seeks to negotiate resolution of a dispute. Many of these other practices involve a one-sided pursuit of truth, without acknowledgment that there may be multiple valid perspectives on a particular topic. Dialogue is often portrayed as complementary to deliberation, which is a process that uses purposeful decision making. A detailed description of how practitioners in the field define dialogue can be found on the National Coalition for Dialogue and Deliberation Website (NCDD, 2007c). Dessel, Rogge, and Garlington (2006) offer a summary of key community and academic-based intergroup dialogue centers that implement intergroup dialogues in a variety of settings and offer dialogue training. Although the fields of mediation and deliberation often overlap and intersect with intergroup dialogue in terms of goals, their history and methods are significantly different. Therefore, this article focuses on the practice of intergroup dialogue as a conflict reduction method. 


\section{Theoretical Basis for Intergroup Dialogue}

Theory is a critical aspect of any intervention, as it places practice within a context of history, previous research, hypotheses, and systematic testing of expected outcomes. Theory can be both inductive when it is derived from data and observations, or deductive when it is tested to examine evidence of its accuracy (Rubin and Babbie, 2005). The proposition that intergroup dialogue can facilitate positive changes in prejudicial attitudes or behaviors and improve polarized relationships stems from a number of fields, among them social work, political science, social psychology, and communications. This work has focused on interpersonal attitudes, bias, and stereotypes as well as group conflict, with research indicating a link between prejudicial attitudes and discriminatory or violent behavior (Masser and Moffat, 2006; Parrott, Zeichner, and Hoover, 2005). Primary theories that explain how intergroup dialogue ameliorates conflict center on concepts of social identity, attitudes, social constructionism, self-reflection and perspective taking, anxiety reduction, learning, friendship potential, power balance, and cooperation.

Ross (2000) has delineated six major theories in ethnic-based conflict resolution practice: community relations, principled negotiation, human needs, psychoanalytically rooted identity, intercultural miscommunications, and conflict transformation. In this typology, he discusses intergroup dialogue in relation to two of these theories, human needs and identity. Intergroup dialogue is seen as a method used to recognize common needs, goals, and perspectives, and as a process for highlighting how social identity influences worldviews and sociopolitical relationships (Ross, 2000).

Researchers in the fields of social psychology and intergroup relations have grappled with how to reduce conflict between groups who hold historically opposing social identities and view others as an "outgroup," that is, a member of another social group (Dovidio and Gaertner, 1999). Allport's widely cited contact hypothesis (1954) stated that intergroup contact results in positive effects if four conditions were present: (1) equal group status within the group encounter, (2) common goals, (3) cooperative interactions, and (4) support of authorities, meaning that contact between two groups is promoted by those with social influence and power.

Pettigrew (1998) extended the testing of this contact theory and addressed limitations of selection bias to examine processes involved in intergroup contact. He found that change occurs through learning about outgroups, the opportunity for reappraisal and recategorization of outgroups, 
generation of empathy and positive emotion, and the potential for friendships. Pettigrew concluded that individual differences and societal norms influence intergroup contact effects and affirmed the importance of providing opportunities for intergroup friendships and then measuring longitudinal effects. Most recently, a meta-analytic test of intergroup contact theory with 713 independent samples from 515 studies confirmed the strength of intergroup contact to reduce prejudice among a variety of groups (Pettigrew and Tropp, 2006).

Cognitive learning and social identity theories add to an understanding of how intergroup dialogue reduces conflict and promotes relationship building. Approaches to attitude change have included manipulating ingroup and outgroup perceptions (Crisp 2005), facilitating intergroup contact and its impact on social identity roles and potential for cross-group friendships (Brewer, 1996; Pettigrew, 1997), evoking empathy (Batson, Chang, Orr, and Rowland, 2002), and education and self-reflection (Dovidio and Gaertner, 1999). Rudman, Ashmore, and Gary (2001) conducted a study in which interventions to change cognitive and affective processes resulted in decreased implicit and explicit prejudice scores. Activation of conscious egalitarian beliefs and intention to control prejudicial behaviors can mediate the relationship between automatic prejudice and biased behavior (Dasgupta and Rivera, 2006).

Research has indicated that intergroup prejudice is often based on construal of perceived differences rather than actual differences (Robinson, Keltner, Ward, and Ross, 1995). Intergroup contact that fosters opportunities for "self-revealing interactions" has been shown to facilitate superordinate identity formation and reduce bias (Gaertner, Dovidio, and Bachman, 1996). Dialogue processes afford this opportunity and have been shown to facilitate some of these crucial components of attitude change, namely critical self-reflection and perspective taking (Gurin, Dey, Hurtado, and Gurin, 2002; Gurin, Nagda, and Lopez, 2004; Nagda, 2006; Nagda and Zuniga, 2003). In this manner, dialogue is a critical opportunity for participants to closely examine the socially constructed norms and ideologies that guide their (often unconscious) beliefs.

Intergroup contact gives rise to extreme anxiety for both dominant and nondominant groups in society (Stephan and Stephan, 2001). Intergroup dialogue creates the opportunity for safe and positive interactions between groups that may reduce the dominant group's anxiety and threat that has been shown to positively correlate with negative attitudes toward marginalized groups (Comerford, 2003; Moradi, van den Berg, and Epting, 
2006). Members of nondominant groups have also reported positive experiences from participating in intergroup education and dialogue, and they note the importance of these interventions (Gurin, Peng, Lopez, and Nagda, 1999; Nagda, Kim, and Truelove, 2004). Saguy, Pratto, Dovidio, and Nadler (in press) and Brown and Mistry (2005) point out that despite power differentials between dominant and marginalized groups, intergroup contact can be effective if it incorporates recognition of systematic imbalances of power, perceptions, and goals between the two groups.

Conflict resolution practitioners who work with nations or ethnic groups recognize the challenges inherent in affecting such large-group processes. Even in these situations, however, small group process using dialogue methods, or "psychopolitical dialogues," is hypothesized to produce peaceful outcomes (Volkan, 1998). This theory is based on the opportunity dialogue affords to work out large social identity conflicts in safe interpersonal interactions through active listening that facilitates the experience of being heard by the "other," recognition and appreciation of the struggles of the other, and illumination of hidden tensions. This may potentially lead to such groups working collaboratively toward change.

The theories discussed here span the cognitive, affective, and behavioral spectrum in describing how intergroup contact and dialogue can reduce interpersonal and group conflict. Most theories focus on individuallevel processes and change. Additional group and societal factors are identified in regard to authority sanctions and power differentials. Although there seems to be clear understanding of the psychological processes involved, there is less theoretical attention given to how these processes translate into larger group, institutional, and structural dynamics and change.

\section{Goals of Intergroup Dialogue}

The goals of intergroup dialogue implementation can be derived from research questions and discussions about purposes and intentions of the work. It is important to identify and operationalize goals to determine if dialogue has achieved its aims. The National Coalition for Dialogue and Deliberation (NCDD, 2007b) identified four primary goals of dialogue: exploration, conflict transformation, decision making, and collaborative action. NCDD's Engagement Framework (2007a) further delineates which dialogue methods are appropriate to employ on the basis of purposes and issues. The Public Conversations Project (2006), a well-known 
and respected organization that conducts dialogue work in a variety of settings, has identified a number of goals of intergroup dialogue. In their most recent publication, project staff delineated these goals:

1. The promotion of generous listening, reflection before speaking or acting, and genuine thoughtful speaking

2. Participants' recognition and commitment to relational intentions, long-range purposes and capacity to shape what happens

3. Participants' ownership of the process

4. Openness to others and mutual recognition

5. Recognition of the complexity of self and other, and an inquiring stance

6. A sense of safety, security, and trust

7. Equal conversational power [Herzig and Chasin, 2006, p. 141]

In the geopolitical realm, the United Nations Development Programme's (UNDP) Democratic Dialogue Project is developing a dialogue typology that describes and analyzes their work. UNDP staff note an increased interest in the nonprofit sector in evaluation of conflict resolution work, primarily driven by two shifts in nonprofit international aid and UN development programs. The first change is that funders are requesting more accountability and cost effectiveness reporting and are expressing concurrent interest in furthering the knowledge base of effective practices. The second change is recognition of a proliferation of international interethnic conflicts and that traditional means of resolving intergroup tensions have not been effective (WSP/UNDP-DRLAC, 2003). Researchers have mapped the dialogue processes being implemented in regions around the globe in the form of case studies, building a valuable knowledge base for those who wish to further this practice (PNUD, 2004b). The goals of these far-reaching international dialogues in Guatemala, South Africa, Uruguay, and other countries are to deal with critical sociopolitical events, address challenges and problems of the times, and promote long-term change (Diez-Pinto, 2003). Other UNDP dialogue goals have included change in attitudes, communication and relationships, change in behavior, formal peace agreements, covenants or declarations, creation of effective peace institutions, participant satisfaction and requests for more dialogue, and increased local capacity for conflict management (PNUD, 2004a). 
Halabi (2000) described the goals of the School for Peace model of Arab-Jewish intergroup dialogue. He stated that rather than attempting rational conflict resolution, the school's dialogues aim to promote a genuine exchange about the inequities that exist for Arabs in Israel. Their dialogues to reduce intergroup conflict between Palestinians and Israelis have focused on realistic conflict that stems from competition for resources, and on shifts in ingroup favoritism according to social identities. Halabi noted that relative power and privilege must be acknowledged in any intergroup dialogue. He emphasized that participants must have secure group identities and be willing to engage in genuine dialogue about peaceful coexistence and the pursuit of social change.

Goals for academic-based dialogues have included increased motivation for intergroup learning, confidence in engaging in social action, increased learning about the social group identities of self and other, and reducing stereotypes and prejudice (Miller and Donner, 2000; Nagda, Kim, and Truelove, 2004; Nagda and others, 1999). Dialogue practitioners often seek to reduce prejudice and its assumed consequences of discrimination and oppression (Nagda and Derr, 2004; Schoem and Hurtado, 2001). Researchers in the field of prejudice reduction have examined the relationship between stereotypes and prejudice (Stephan and Stephan, 1996) and between prejudice and discrimination (Schutz and Six, 1996). Other researchers in this field have measured qualities attributed to outgroups, expectations about intergroup conflict, preferred responses to conflict, and emotional responses to conflict (Bizman and Hoffman, 1993). Intergroup anxiety in interracial interactions has been measured as well (Stephan and Stephan, 1985; Stephan, Ybarra, and Bachman, 1999). Reduction of intergroup anxiety, prejudice, and other problematic manifestations of group identity interactions may all be desired intergroup dialogue outcomes.

When dialogue is used as an integral part of a deliberative democracy process, its goals may be inclusion of the voices of significant stakeholders, elicitation of values and assumptions, opportunity for reflection and learning, and the crucial development of relationships (Ryan and DeStefano, 2000). Mansbridge and colleagues touched on an important point when they describe the "interlocking relationship between group atmosphere and task productivity" (Mansbridge, Hartz-Karp, Amengual, and Gastil, 2006, p. 36). Other goals of dialogue may be cultural accommodation or agreement to enter into a deliberative phase of public engagement (Levine, Fung, and Gastil, 2005). In highly polarized situations, differences in cultural 
norms may contribute to participants' difficulty in communicating with and understanding each other. Dialogue goals of greater awareness of others' positions, values, and views may lead to creation of an opportunity for deeper levels of understanding, coexistence, and consensus building.

\section{Research on Intergroup Dialogue Outcomes}

Methods for this literature review followed guidelines used by previous authors (Cohan, Chavira, and Stein, 2006; Ohmer and Korr, 2006). A search of several databases was conducted: PsycINFO, Social Sciences Abstracts, Sociological Abstracts, and ComAbstracts, using the terms "intergroup dialogue," "dialogue," "evaluation," "outcomes," "results," and "research.” Reference lists of articles located were examined for dialogue evaluation references. The Websites of nine prominent national dialogue programs were reviewed for publications on the topic of evaluation. They were the International Institute for Sustained Dialogue (2006), National Coalition for Dialogue and Deliberation (2007b), National Issues Forums (2006), the Public Conversations Project (2006), Public Dialogue Consortium (2006), Search for Common Ground (2006), Study Circles Resource Center (2006), Western Justice Center Foundation (2006), and the World Café (2006).

A total of twenty-three studies conducted between 1997 and 2006 were located for this review. Inclusion criteria consisted of studies that used both quasi-experimental and pre-experimental research designs, and quantitative and qualitative data collection methods. Pre-experimental designs, such as case studies, pre- and post-surveys, and posttests only with nonequivalent groups do not control for most threats to internal validity such as passage of time or selection bias (Rubin and Babbie, 2005). Quasiexperimental designs attempt to control for some of the validity threats through use of pre- and posttests with nonequivalent comparison groups and time-series designs (Rubin and Babbie, 2005). No experimental design studies using random assignment were located. Three studies used mixedmethods data collection. Eight studies were conducted by a related set of coauthors in academic settings.

Studies included in this review examine dialogues implemented in academic, community, and international settings. These dialogues address issues ranging from racial and ethnic conflict to polarized social topics and civic engagement to interethnic war.

All studies are summarized in an intergroup dialogue evaluation compendium (Table 1) that compiles data on sample populations and response 
rate, research questions and goals, research design and methods, quantitative and qualitative data collection tools, and outcome variables. Consolidation of this data will constitute an important resource for practitioners in future evaluation of dialogue encounters and serve to enhance the knowledge base of dialogue evaluation work.

\section{Summary of Methodologies and Research Designs}

Social science methodology holds the key to unlocking the problems faced by society (Schutt, 2004). As such, it is critical to examine the methodology of any research study that presents findings and implications, in order to assess the reliability and validity of such findings and build on the important work being done. Twenty-one studies are reviewed and discussed here. These studies are grouped according to academic, community, and international settings.

In academic settings, two related studies (Gurin, Peng, Lopez, and Nagda, 1999; Gurin, Nagda, and Lopez, 2004) used a control group and a longitudinal design to examine outcomes of participation in multicultural intergroup dialogues. These quasi-experimental designs, though not able to establish causality of outcomes, were the strongest methods used. In addition, two other studies added a longitudinal aspect as well to their pretest-posttest survey designs, which yields important data on sustained effects of dialogue over time (Gurin, Dey, Hurtado, and Gurin, 2002; Hurtado, 2005). Other studies used pre-experimental designs, including formative and summative program evaluation (Nagda, Peng, and Lopez, 1999), a self-administered postsurvey design (Miller and Donner, 2000), and one-group pretest-posttest design (Trevino, 2001; Nagda, Kim, and Truelove, 2004; Nagda, 2006; Nagda and Zuniga, 2003). Formative program evaluations focus on improving implementation, planning, and development, while summative program evaluations are concerned with evaluating success (Rubin and Babbie, 2005). Khuri (2004a) and Halabi (2000) described exploratory case study designs that used qualitative data to analyze outcomes for Arab and Jewish dialogue participants.

In community settings, designs have included a range of pre-experimental methods using interviews, surveys, secondary data analysis, and focus groups (DeTurk, 2006; Hartz-Karp, 2005; LeBaron and Carstarphen, 1997; McCoy and McCormick, 2001; Nagda, McCoy, and Barrett, 2006; Pan and Mutchler, 2000; Rodenborg and Huynh, 2006). Both quantitative 
and qualitative data collection methods have been used, with postdialogue data collection being the most widely used method. This is understandable considering the significant amount of time, energy, and cost involved in evaluating community-based dialogues. These studies permit in-depth analyses on use of intergroup dialogue to improve societal conflicts on a range of topics from abortion to race relations to citizen engagement.

When dialogue has been evaluated for its effects on international and interethnic conflict, participatory action research and case study designs have been used (Abu-Nimer, 1999, 2004; Diez-Pinto, 2004; Pruitt and Kaufer, 2004; Munyandamusta, Mugiraneza, and Van Brabant, 2005; Noto and others,, 2004; Saunders, 2003; Thillet de Solorzano, 2004). Evaluation methods for UNDP dialogues, which have been termed "situational, reflective and generative," have included participatory action research, case studies, and interviews (Pruitt and Kaufer, 2004; Thillet de Solorzano, 2004). A heuristic approach and emergent design in dialogue evaluation may take the form of "reflective practice," whereby each stage of the dialogue process involves participatory planning in describing the outcomes for the next stage (Munyandamusta, Mugiraneza, and Van Brabant, 2005).

Overall, the primary research methods that have been used to examine dialogue outcomes are pre-experimental designs. Two studies used a quasiexperimental design to measure intergroup dialogue outcomes. Many studies located used a mixed-methods data collection approach to gather both quantitative and qualitative data, using pre- and post-surveys, qualitative interviews and observations, program evaluations, and case studies (Rubin and Babbie, 2005). Dialogue practitioners and researchers are using a range of methods to gain much-needed insight into the effectiveness of intergroup dialogue. However, there is less longitudinal work being done to examine long-range effects. Additionally, qualitative data analysis methods have been very limited, and more rigorous approaches to data collection such as recording interviews and coding would contribute significantly to the knowledge base.

\section{Summary of Participants}

Accurate and relevant sample description, including details about response rates, attrition, and missing data in quantitative analyses, must be addressed in any research study to determine the representative nature of the sample and the generalizability of results (Schutt, 2004). All of the studies reviewed used convenience samples rather than random samples. 
The most rigorous intergroup dialogue evaluation research has focused on populations of students in academic settings. However, there is also significant work being conducted in community and international venues.

Eleven studies were carried out in academic settings, with most samples of college students ranging from 15 to 211 participants. Three studies had significantly large samples $(1,383$ to 4,403$)$ of college students (Gurin, Dey, Hurtado, and Gurin, 2002; Gurin, Nagda, and Lopez, 2004; Hurtado, 2005). One study of 80 participants also included faculty and staff in their dialogues (Miller and Donner, 2000). A few of the larger studies included race and gender demographics, but most did not. Response rates were published for six studies, ranging widely from 35 percent (Hurtado, 2005) to 100 percent (Nagda and others, 1999), with most fairly good at around 75 percent.

In community settings, intergroup dialogue is often implemented in order to address conflict around a social issue. For example, in the studies reviewed dialogues were convened around the topics of abortion, the quality of public education, community planning, and racism. Most studies engaged participant samples that ranged from 15 to 1,100 citizens. Nagda and colleagues' evaluation of the Mix It Up dialogues (2006), a program initiated by Study Circles and the Teaching Tolerance Project (http://www.tolerance .org/teach/mix_it_up/dialogues.jsp) designed to help secondary school students cross social boundaries and improve intergroup relationships, used a sample of 103 educators and 434 students. The educator response rate was 83 percent, with no response rate reported for the students.

Research that evaluates dialogues designed to resolve interethnic conflict has been conducted by Mohammed Abu-Nimer, who examined dialogue outcomes for Arabs and Jews in the Middle East, and by the UNDP. Abu Nimer's sample (1999, 2004) included 156 facilitators, administrators, participants, and community leaders involved with fifteen coexistence programs between Arabs and Jews in Israel. The UNDP has implemented a Democratic Dialogue Program that brings dialogue practices to approximately twenty conflict-ridden countries. These samples included citizens and community leaders in Guatemala, Panama, the Philippines, Argentina, Peru, and Tajikistan (Diez-Pinto, 2004; Noto and others, 2004; Saunders, 2003).

There is a range of settings in which dialogue evaluation work is being conducted, reflecting the applicability of outcomes to a variety of populations. Total sample size varies greatly, and although dialogue is typically delivered in small group units of eight to ten people there appears to be a 
lack of clarity across studies for a protocol of number of participants. Although dialogue is rooted in Western cultural practices, it has been translated into use for interethnic conflict among societies ranging from Middle Eastern to Central and South American. Those who are interested in promoting and enhancing civic engagement have also found dialogue a promising method (DeTurk, 2006; Hartz-Karp, 2005; LeBaron and Carstarphen, 1997; Pan and Mutchler, 2000).

\section{Summary of Data Collection Methods and Measures}

There are a variety of quantitative and qualitative data sources available in social science research. The choice of data collection methods may be driven by research questions, the researcher's method orientation, or the setting in which the study is carried out. The outcome studies for dialogue interventions examined in this review used both quantitative and qualitative data collection methods. Twelve studies employed quantitative surveys, with no one survey used consistently across studies. A related set of coauthors, Nagda, Gurin, Hurtado, and colleagues, used similar items or measures. Seven studies published survey items or full survey descriptions, with a few reporting on reliability and other psychometric properties (Gurin, Dey, Hurtado, and Gurin, 2002; Gurin, Nagda, and Lopez, 2004; Gurin, Peng, Lopez, and Nagda, 1999; Miller and Donner, 2000; Nagda, 2006; Nagda, Kim, and Truelove, 2004; Nagda and Zuniga, 2003). Publication of instruments is important because it offers a useful starting point for others who would like to evaluate dialogue outcomes.

Gurin, Nagda, and Lopez (2004) used a survey that measured nine constructs including perspective taking, nondivisiveness of difference, perception of commonalities of values, participation in politics, and mutuality in learning about one's own and other groups. Reliability scores for each subscale were fair to good (.61 to .84). Gurin, Peng, Lopez, and Nagda, (1999) examined outcome variables of perceived intergroup divisiveness and commonality, positive and negative views of conflict, amount and quality of interethnic or racial interactions, emotions related to interethnic interactions, and views on the multicultural policies of the university. Interaction effects were examined for the variable of strength of group identity for dominant (white and male) and nondominant groups (African American, Latino/a, Asian American, and women). The authors reported good alpha reliability scores (.68 to .88) for racial and gender identity 
measures, and item analysis results regarding internal validity for indices of centrality, pride, importance, and common fate.

Miller and Donner (2000) used a self-administered postsurvey design with fifteen scaled items and open-ended items designed to describe and understand the meaning of the dialogues for participants. Nagda, Kim, and Truelove (2004) and Nagda and Zuniga (2003) used surveys designed to examine the effects of participation in intergroup dialogue on critical social awareness, dialogic communication, beliefs about conflicts and building cross-cultural communication, and intention to take action regarding racism. A unique analysis of dialogue processes and outcomes, conducted by Nagda (2006), employed factor analysis to establish construct validity for the hypothesized communication processes involved in dialogue, and hierarchical regression analyses to determine mediation effects of dialogue on outcomes of bridging differences.

Qualitative methods of data collection regarding dialogue outcomes include interviews, qualitative surveys, focus groups, and observation. These methods have been applied in community, international, and academic settings. Khuri (2004a) and Halabi (2000) gathered qualitative data from Israeli and Palestinian students in higher education academic settings, and Nagda, McCoy, and Barrett (2006) used qualitative interviews to gather information on crossing intercultural social boundaries in a secondary school setting. Case study approaches often use grounded theory and then participant observation and interviews. DeTurk (2006) used this approach to examine the effects of participation in a municipal intergroup dialogue program designed to improve alliance building, as did LeBaron (1997), who interviewed participants in national dialogues about abortion. Hartz-Karp (2005) examined civic participation for eleven hundred citizens, and Rodenborg and Huynh (2006) analyzed outcomes for fifteen members of an intercultural dialogue who met over six years.

Many researchers used qualitative surveys to understand the processes and outcomes of dialogue as an intervention. Qualitative approaches often reflect a valuable constructivist or utilitarian perspective (Denzin and Lincoln, 2000) and permit particularly valuable insights into participant experiences for small-group interventions such as intergroup dialogue. McCoy and McCormick (2001) and Pan and Mutchler (2000) collected such data to examines outcomes of Study Circles, one of the most widely implemented dialogue programs. Researchers around the globe have used qualitative interviews to study interethnic conflict (Abu-Nimer, 2004; 
Diez-Pinto, 2004; Munyandamusta, Mugiraneza, and Van Brabant, 2005; Noto and others, 2004; Pruitt and Kaufer, 2004; Saunders, 2003; Thillet de Solorzano, 2004).

In the studies reviewed, quantitative data collection instruments were published more often than qualitative instruments. Inclusion of instruments in a manuscript presents invaluable information for researchers wishing to replicate the study or evaluate other dialogues. The quantitative instruments furnished by Gurin and Nagda have been well validated and are important tools for assessing improvement in intergroup conflict.

\section{Summary of Dialogue Interventions}

The description of any intervention that is used to address a problem is the key for others to use the intervention to address similar problems. In the studies reviewed here, diverse organizations and people implemented dialogue as a method of resolving conflict. Dialogues were convened and facilitated by professional organizations such as the Public Conversations Project, by academics such as Khuri (2004a, 2004b), and by government entities (DeTurk, 2006).

Many approaches established ground rules that promoted trust, communication, and relationship building (DeTurk, 2006; Diez-Pinto, 2004). Some dialogues, particularly those in academic settings and those that consisted of Palestinian and Israeli participants, were cofacilitated by two people who represented the identity groups of participants, while others were facilitated by one person or many people across groups (Hartz-Karp, 2005). Two authors identified stages of the dialogues that carried participants through levels of addressing the issues, including critical attention to emotions (Halabi, 2000; Khuri, 2004a, 2004b). Dialogues also addressed topics of stereotyping, prejudice reduction, and other experiential exercises with combined attention to both affective and cognitive processes (AbuNimer, 1999; Nagda, Kim, and Truelove, 2004).

In each study, some form of dialogue was used as an intervention to address the stated issues or goals. But how a dialogue approach, method, or process was implemented varied widely, and in most studies the specific dialogue protocol was not clearly delineated. Consequently, it is extremely difficult to summarize the dialogue methods across studies. Lack of a clear description of how dialogue was implemented creates difficulty in replicating studies to confirm their effectiveness. 


\section{Summary of Dialogue Outcomes}

To understand whether a particular intervention has been effective or achieved its goals, it must be assessed in some way. As previously stated, outcome evaluations are costly and time-consuming and often meet with resistance. However, researchers who seek to understand the effect and outcomes of participation in intergroup dialogues have discovered multiple benefits of this approach to improving intergroup relations, as well as numerous questions that remain to be answered.

The two quasi-experimental studies conducted in academic settings found important effects for participants in dialogues. Furthermore, these studies examined and found group differences based on ethnicity and race. White students increased their perspective taking, sense of commonality regarding the other groups, capacity to view differences as compatible with democracy, and political involvement such as more frequently supporting multicultural and affirmative action policies. White students also reported an effect of less positive feelings regarding their interactions with other white students (Gurin, Peng, Lopez, and Nagda, 1999; Gurin, Nagda, and Lopez, 2004), a phenomenon that often occurs for participants challenged to examine their own privilege (Goodman, 2001).

For students of color, each group evidenced increased scores on all outcomes variables, with the exception of perspective taking of whites. African American students evidenced this perspective-taking outcome, while Asian and Latino/a did not. Effects for students of color were perceptions of less intergroup divisiveness and holding more positive views of conflict. These students also reported having increased positive relationships with white students four years later, and perceptions of greater commonality with white students (Gurin, Peng, Lopez, and Nagda, 1999; Gurin, Nagda, and Lopez, 2004).

Pre-experimental and qualitative studies in academic settings have also found positive results of intergroup dialogue participation. For example, students in academic college settings have reported increased learning about the perspectives of people from other social groups, development of analytical problem solving skills, valuing new viewpoints, understanding the impact of social group membership on identity, gaining increased awareness of social inequalities, and raised awareness of racial identity for both white students and students of color (Gurin, Dey, Hurtado, and Gurin, 2002; Hurtado, 2005; Nagda and others, 1999; Nagda and Zuniga, 2003). Other researchers note results of increased hope that people from another 
racial background could listen to each other (72.8 percent of students of color, 97.6 percent of white students; Miller and Donner, 2000). Recognition of multiple perspectives and clarifying one's own beliefs has been another significant outcome (Khuri, 2004a).

A few studies in particular examined the issue of power imbalances and perspectives of dialogue for nondominant group members. As with Gurin, Peng, Lopez, and Nagda (1999), two pre-experimental studies (Nagda, Kim, and Truelove, 2004; Nagda and Zuniga, 2003) also found that students of color rated dialogues as more valuable and thought more positively about conflict than did white students. In a secondary school setting, students of color, more than white students, reported being able to share their perspectives and rated their learning as higher (Nagda, McCoy, and Barrett, 2006). Interestingly, in another study only about half of the students of color in a college setting compared with all of the white participants felt the groups could learn from each other (Miller and Donner, 2000). Halabi (2000) found that Arab students gained the ability to express their oppression more assertively, and Jewish students recognized their role as oppressors and Arab students' oppression.

One study examined outcomes for the Mix It Up dialogue program, initiated by Study Circles and the Teaching Tolerance Project to help secondary school students cross social boundaries and improve intergroup relationships. Results for educators indicated that more than three-fourths of them reported students said dialogues were a positive experience, and that students held honest discussions and evidenced more respect and were more willing to cross social boundaries. Half of the educators saw the level of conflict go down in the schools and attributed this to the dialogues. However, three-quarters of educators did not see students initiating actions on tolerance projects; nor did they note any impact of dialogue on institutional policy or curriculum. Results from student surveys indicated that students experienced positive changes such as raised awareness about cliques and social boundaries. Nevertheless, there was limited agreement about the opportunity to talk openly about issues of concern, or about courses of action to change regarding peer conflict. These outcomes indicate the need for adults to take the lead in addressing prejudicial attitudes and behavior in public school settings.

In community settings outcomes of dialogues have implications for individual, interpersonal, and systemic change. Outcomes such as stereotype reduction, increased understanding and empathy, recognition of the impact of ethnicity on individual identity and group interactions, 
increased perspective taking, increased awareness about structural power relations, and complex thinking about diversity all indicate important attitudinal change. Outcomes of improved communication and cross-racial interaction skills, provision of support and development of friendships, and uncovering common ground and initiating joint action on shared issues of concern indicate the potential for conflict resolution and social change actions (DeTurk, 2006; LeBaron and Carstarphen, 1997; McCoy and McCormick, 2001; Pan and Mutchler, 2000; Rodenborg and Huynh, 2006). Many who participated in these dialogues evidenced an increase in civic engagement and indicated they would participate again (Hartz-Karp, 2005).

Dialogue has been used to address large-scale interethnic conflicts. Abu-Nimer (1999) conducted a program evaluation over a six-year period with 156 facilitators, administrators, participants, and community leaders involved with fifteen coexistence programs between Arabs and Jews in Israel. Results of this extensive evaluation indicated that, in part, individuals experienced changes in perceptions of each other and the conflict, an increased sense of knowing each other culturally and personally, raised awareness of Arab-Jewish relations in Israel, and positive experiences of their interactions. Diez-Pinto (2004) evaluated dialogues conducted in Guatemala that aimed to promote trust and establish a foundation for a long-term national peace agenda. She found that dialogues influenced both personal and national processes through breakdown of stereotypes, facilitation of personal relationships that would not have otherwise formed, and establishment of trust that led to the start of consensus building. Other UNDP researchers have described case studies of dialogues undertaken in Panama, the Philippines, Argentina, Peru, and Guatemala (Noto and others, 2004). Results indicated that dialogues fostered important changes such as critical acknowledgment of social policies, launching of a program that supported two million families living below the poverty line, and consensus building regarding prescription drug reform.

Saunders (2003), who developed and reported on the Inter-Tajik Dialogue from 1993 to the present, noted that sustained dialogue and relationship building work occurs within complex multilevel political processes. These dialogues paved the way for negotiation and generated a Commission on National Reconciliation. Saunders emphasized the necessity of ongoing participatory self-evaluation "by the people whose lives are at stake," with participants identifying desired outcomes and next steps at each level (2003, p. 89). 
Racial or ethnic intergroup relationships were the primary variables of interest in most studies. In terms of reducing prejudicial attitudes of dominant groups, shifts for white students in these studies are the most salient outcomes. For the two studies that used control groups (Gurin, Peng, Lopez, and Nagda, 1999; Gurin, Nagda, and Lopez,2004), it appears that dialogue participation facilitated perspective taking and a sense of commonality for both dominant and marginalized groups. Nagda's study (2006) confirmed this possibility for dialogue to facilitate relationships and alliance building. Qualitative studies highlighted important outcomes of reduction in stereotypes, increased perspective taking, and improved crosscultural relationships.

\section{Discussion}

The research reviewed here presents a broad and ambitious picture of studies that seek to explain the complex processes and outcomes of intergroup dialogue work. Overall, methodological strengths of these dialogue outcome studies are identification of relevant dependent and control variables, use of both descriptive and inferential statistical methods to analyze the data, and in two cases use of a control group. Three studies reported on reliability and validity for scores and scales. Researchers who have used preexperimental methods have gathered important exploratory data about individual experiences and programmatic outcomes of intergroup dialogue work. Some methods, such as participatory action research, can elicit the "real rather than perceived interests" of those whom conflict most affects (Ryan and DeStefano, 2000, p. 7). The qualitative studies yielded detailed portrayals of participant experiences, and the ethnographic nature and potential of such evaluation work creates an important window into the dialogue process for participants.

There are a number of limitations to the research on intergroup dialogue. The first pertains to the use of quasi- or non-experimental designs. Without random assignment or a matched control group design, it is difficult to confirm dialogue's potential contribution to changes in attitudes. Additionally, studies using international dialogue samples are primarily evaluated through case studies, thereby limiting conclusions about the effects of these dialogues. Another limitation is the use of convenience samples and the fact that response rates are not reported for many of the studies that used surveys, as well as the variation in response rate ranging from 35 percent to 80 percent. This limits generalizability and conclusions about 
results. As well, a range of survey measures was used with none being employed more than once, so there is no consistent measurement instrument available to practitioners who want to assess dialogue outcomes. Possible biases from attrition, test or researcher reactivity, and social desirability were not addressed in most studies. In three of the studies, it was more difficult to discern the distinct effects of dialogue when this experience was embedded within a multicultural learning program. Overall, standardized and replicable evaluation methodologies are limited, and lack of random assignment challenges assumptions of causality regarding dialogue outcomes. Finally, inconsistent implementation of a dialogue protocol makes it difficult to assess effects across studies or replicate the methods used.

This review of the body of research on intergroup dialogue outcomes constitutes an important window into what has been accomplished in this field and the challenges yet to come. The most controlled studies occurred in academic settings with undergraduate or graduate student samples. This population is a critical one to reach regarding prejudice and intercultural relations. An important contribution is the differential outcome effect of intergroup contact for dominant and nondominant social groups, one that has been noted in previous research (Hyers and Swim 1998; Pettigrew and Tropp, 2006). However, much remains to be done in terms of improved evaluation of intergroup dialogue, as discussed in the recommendations.

\section{Recommendations}

Intergroup dialogue has been used to resolve conflicts, improve relationships, and initiate social justice work. However, a significant portion of dialogue work occurs with little attention paid to assessing process or outcomes. Further research is necessary in order to increase our understanding of how this type of engagement may improve intergroup relations. What follows here are recommendations for steps dialogue practitioners in various settings and with differing perspectives on evaluation can take to further our learning about whether and how dialogue processes are achieving desired results.

First, there should be increased evaluation in community settings. The most rigorous evaluation research has taken place in academic settings, where there is support and structure for studying the dialogue process. Researchers in these settings have been able to examine whether dialogue is achieving its outcomes. On the other hand, community practitioners of dialogue work and nonprofit organizations have engaged less in evaluation 
research of dialogue practices. These groups may not have the resources, time, or training opportunities to conduct evaluation of dialogue outcomes. Increased evaluation of intergroup dialogue work in community and field settings will not only contribute to better understanding of its processes and improve its effectiveness but also enable these practitioners to secure funding to further examine the potential of the work.

Second, in academic and community settings that allow controlled analysis, quasi-experimental and experimental designs should be used when possible. Stephan, Renfro, and Stephan (2004) and Stephan and Stephan (2001) present comprehensive recommendations for research approaches that evaluate intergroup relations programs. Use of experimental designs furnishes substantial documentation of effects that can be attributed solely to intergroup dialogue, thereby strengthening the potential for future use and support of dialogue work.

Third, dialogue methods should use established dialogue protocols, measurement tools, and rigorous quantitative and qualitative analyses. Established dialogue protocols should be described and made available for practitioners to use in replicating as well as refining the method. The Public Conversations Project (Herzig and Chasin, 2006) offers such a manual for community-based dialogues. A number of academic centers and faculty supply syllabi for academic-based dialogues (Duah-Agyeman and Hamilton, 2006; Spencer, 2004). Rigorous analysis methods should employ evaluation tools such as previously validated quantitative measures or rigorous qualitative data analysis methods such as audio recording, coding, and computer-assisted analysis. Practitioners and researchers may take advantage of an array of research designs and data gathering methods, among them statistical analysis, content analysis, ethnography, interrater correlation, participatory action research, and program evaluation (Denzin and Lincoln, 2000; Dessel, Rogge, and Garlington, 2006; Rubin and Babbie, 2005). Focus groups, in particular, are an opportunity to gather in-depth and detailed data on participant experiences from nondominant groups who historically have been excluded from traditional research (Bamberger and Podems, 2002; Brown, 2000).

For researchers interested in the descriptions qualitative data collection offers, or settings that are more conducive to these methods, ethnography, discourse analysis, focus groups, observations, and case studies may be used (Berg, 1998; Steinberg, 2004). Process evaluation and discourse analysis address important ethical issues such as power imbalance and culturally competent dialogue design (Dessel, Rogge, and Garlington, 2006; Dessel, 
2006; Suleiman, 2004; Thompson-Robinson, Hopson, and SenGupta, 2004) and serve to illuminate how identity, culture, and power are reproduced in and mediated by language (Rogers and others, 2005).

Technological advances in data collection, particularly in attitude research, may also be used to address limitations such as social desirability. Computer-assisted survey methods designed to ensure anonymity have been used, for example, in evaluating online deliberative dialogues about national issues during the 2000 political campaign (Price and Capella, 2002). Use of computerized Implicit Association Tests (IATs), which measure attitudes on the basis of response time, circumvent both self-censorship and external response bias and may even tap into unconsciousness attitudes (Lane, Banaji, Nosek, and Greenwald, 2007).

Fourth, development and testing of measurement tools is a key component of evaluation. In community settings, organizations such as the Study Circles Resource Center have begun to implement more intentional and standardized evaluation methods, notably use of postsurveys. The coauthors recently developed an evaluation tool for an intergroup dialogue between national stakeholders in the domestic violence, healthy marriage, and responsible fatherhood fields (Dessel, Rogge, and Joseph, 2006; Ooms and others, 2006). Stephan and colleagues give examples of measurement tools that assess racial attitudes, stereotypes, intergroup anxiety, empathy, and intergroup contact and attitudes (Stephan and Stephan, 2001; Stephan, 2006). Survey and interview questions must be culturally sensitive, and when used cross-linguistically they should be translated and backtranslated for cultural relativity and accuracy.

Other variables that are relevant indicators for intergroup dialogue outcomes and have been measured include causes to which conflict is attributed, views about conflict, and attitudes toward outgroups such as perceived threat, anxiety, and empathy (Bizman and Hoffman, 1993; Phinney, Ferguson, and Tate, 1997; Stephan and Finlay, 1999; Stephan and Stephan, 1996; Stephan and others, 1998). One important variable that has not been given enough attention is the level of predialogue conflict, and how this may mediate attitude change. Measurement of prejudice is a critical dialogue outcome that presents its own challenges in terms of social desirability bias. Use of implicit attitude measures may address these limitations (Olson and Fazio, 2006; Wittenbrink, Judd, and Park, 1997).

The proposed recommendations for dialogue practitioners to improve dialogue evaluation are significant in terms of both theory and methodology. Constructs such as avoiding old unproductive language, perspective 
taking, critical self-reflection on one's own ideas, and identification of new possibilities and shared meaning may be among the hardest to measure, but they are outcomes that present the greatest potential for public decision making and positive social change (Chasin and others, 1996; Dessel, Rogge, and Garlington, 2006; Nagda, 2006; Schoem, 2003). Although the goals of intergroup dialogue are impressive, numerous, and somewhat daunting, they are also necessary components of a just and civil society. Ongoing refinement and understanding of the processes and outcomes of intergroup dialogue may further the achievement of such a society.

\section{References}

Abelson, J., Forest, P.-G., Eyles, J., Smith, P., Martin, E., and Gauvin, F.-P. “Deliberations About Deliberative Methods: Issues in the Design and Evaluation of Public Participation Processes." Social Science and Medicine, 2003, 57, 23-251.

Abu-Nimer, M. Dialogue, Conflict Resolution and Change: Arab-Jewish Encounters in Israel. Albany: SUNY Press, 1999.

Abu-Nimer, M. "Education for Coexistence and Arab-Jewish Encounters in Israel: Potential and Challenges." Journal of Social Issues, 2004, 60(2), 405-422.

Allport, G. The Nature of Prejudice. Cambridge, Mass.: Addison-Wesley, 1954.

Bamberger, M., and Podems, D. Feminist Evaluation in the International Development Context. New Directions for Evaluation, no. 96. San Francisco: JosseyBass, 2002.

Batson, D., Chang, J., Orr, R., and Rowland, J. "Empathy, Attitudes, and Action: Can Feeling for a Member of a Stigmatized Group Motivate One to Help the Group?" Personality and Social Psychology Bulletin, 2002, 28(12), 1656-1666.

Berg, B. Qualitative Research Methods for the Social Sciences. Boston: Allyn and Bacon, 1998.

Bizman, A., and Hoffman, M. "Expectations, Emotions, and Preferred Responses Regarding the Arab-Israeli Conflict: An Attributional Analysis." Journal of Conflict Resolution, 1993, 37(1), 139-159.

Bohm, D. On Dialogue. London: Routledge, 1996.

Brewer, M. "When Contact Is Not Enough: Social Identity and Intergroup Cooperation." International Journal of Intercultural Relations, 1996, 20(3/4), 291-303.

Brown, C. Sociolinguistic Dynamics of Gender in Focus Groups. New Directions for Evaluation, no. 86. San Francisco: Jossey-Bass, 2000.

Brown, A., and Mistry, T. "Group Work with 'Mixed Membership' Groups: Issues of Race and Gender." Social Work with Groups, 2005, 28(3/4), 133-148.

Chasin, R., Herzig, M., Roth, S., Chasin, L., Becker, C., and Stains, R. "From Diatribe to Dialogue on Divisive Public Issues: Approaches Drawn from Family Therapy." Mediation Quarterly, 1996, 13(4), 1-19. 
Cissna, K. N., and Anderson, R. Moments of Meeting: Buber, Rogers, \& the Potential for Public Dialogue. Albany: State University of New York Press, 2002.

Cohan, S., Chavira, D., and Stein, M. "Practitioner Review: Psychosocial Interventions for Children with Selective Mutism: A Critical Evaluation of the Literature from 1990-2005." Journal of Child Psychology and Psychiatry, 2006, $47(11), 1085-1097$.

Collier, P., and Sambanis, N. "Understanding Civil War: A New Agenda." Journal of Conflict Resolution, 2002, 46(1), 3-12.

Comerford, S. "Enriching Classroom Learning About Diversity: Supports and Strategies from a Qualitative Study." Journal of Teaching in Social Work, 2003, 23(3/4), 159-183.

Crisp, R. "Reducing Intergroup Bias: The Moderating Role of Ingroup Identification." Group Processes and Intergroup Relations, 2005, 8(2), 173-185.

Dasgupta, N., and Rivera, L. "From Automatic Antigay Prejudice to Behavior: The Moderating Role of Conscious Beliefs About Gender and Behavioral Control." Journal of Personality and Social Psychology, 2006, 91(2), 268-280.

Denzin, N., and Lincoln, Y. Handbook of Qualitative Research. Thousand Oaks, Calif.: Sage, 2000.

Dessel, A. "Talk Versus Action: The Usefulness of Intergroup Dialogue for Oppressed Groups.” Manuscript in preparation, 2006.

Dessel, A., Rogge, M., and Garlington, S. "Using Intergroup Dialogue to Promote Social Justice and Change." Social Work, 2006, 51(4), 303-315.

Dessel, A., Rogge, M., and Joseph, D. "An Evaluation of the Public Conversations Project's Dialogues: A Pilot Study and Survey Development." Manuscript in preparation, 2006.

DeTurk, S. "The Power of Dialogue: Consequences of Intergroup Dialogue and Their Implications for Agency and Alliance Building." Communication Quarterly, 2006, 54(1), 33-51.

Diez Pinto, E. "Towards the Construction of a Dialogue Typology." Draft. United Nations Development Programme: Regional Bureau for Latin America and the Caribbean: Democratic Dialogue Project (RLA-01-004), 2003. Retrieved June 10, 2006 from http://www.democraticdialoguenetwork.org/ documents.pl?s $=2 ;$ ss $=9$.

Diez Pinto, E. "Vision Guatemala 1998-2000: Building Bridges of Trust." New York: United Nations Development Programme, 2004. Retrieved July 31, 2006 from http://democraticdialoguenetwork.org/documents/view.pl?s=13; ss $=; \mathrm{t}=; \mathrm{f} \_\mathrm{id}=263$.

Dovidio, J. "On the Nature of Contemporary Prejudice: The Third Wave." Journal of Social Issues, 2001, 57(4), 829-849.

Dovidio, J., and Gaertner, S. "Reducing Prejudice: Combating Intergroup Biases." Current Directions in Psychological Science, 1999, 8(4), 101-105.

Duah-Agyeman, J., and Hamilton, J. "Intergroup Dialogue on Race and Ethnicity.” 2006. Available at http://intergroupdialogue.syr.edu/PDFs/RaceSyllabus Sp06.pdf. 
Gaertner, S., Dovidio, J., and Bachman, B. "Revisiting the Contact Hypothesis: The Induction of a Common Ingroup Identity." International Journal of Intercultural Relations, 1996, 20(3/4), 271-290.

Goodman, D. Promoting Diversity and Social Justice: Educating People from Privileged Groups. Thousand Oaks, Calif.: Sage, 2001.

Gurin, P., Dey, E., Hurtado, S., and Gurin, G. "Diversity and Higher Education: Theory and Impact on Educational Outcomes." Harvard Educational Review, 2002, 72(3), 330-366.

Gurin, P., Nagda, B., and Lopez, G. "The Benefits of Diversity in Education for Democratic Citizenship." Journal of Social Issues, 2004, 60(1), 17-34.

Gurin, P., Peng, T., Lopez, G., and Nagda, B. "Context, Identity and Intergroup Relations.” In D. Prentice and D. Miller (eds.), Cultural Divides: Understanding and Overcoming Group Conflict. New York: Russell Sage Foundation, 1999.

Halabi, R. (ed.). Israeli and Palestinian Identities in Dialogue: The School for Peace Approach. Princeton, N.J. : Rutgers University Press, 2000.

Hamburg, D. "Preventing Contemporary Intergroup Violence." In E. Weiner (ed.), The Handbook of Interethnic Coexistence. New York: Continuum, 1998.

Hartz-Karp, J. "A Case Study in Deliberative Democracy: Dialogue with the City." Journal of Public Deliberation, 2005, 1(1), Article 6. Available from http://services.bepress.com/jpd/vol1/iss1/art6.

Herzig, M., and Chasin, L. "Fostering Dialogue Across Divides: A Nuts and Bolts Guide from the Public Conversations Project." 2006. Available from http://www.publicconversations.org/jamsdownload.html.

Hurtado, S. "Research and Evaluation on Intergroup Dialogue." In D. Schoem and S. Hurtado (eds.), Intergroup Dialogue: Deliberative Democracy in School, College, Community and Workplace. Ann Arbor: University of Michigan Press, 2001.

Hurtado, S. "The Next Generation of Diversity and Intergroup Relations." Journal of Social Issues, 2005, 61(3), 593-610.

Hyers, L., and Swim, J. "A Comparison of the Experiences of Dominant and Minority Group Members During an Intergroup Encounter." Group Processes and Intergroup Relations, 1998, 1(2), 143-163.

International Institute for Sustained Dialogue. 2006. Available from http://www.sustaineddialogue.org/.

Isaacs, W. Dialogue and the Art of Thinking Together. New York: Doubleday, 1999.

Khuri, M. "Facilitating Arab-Jewish Intergroup Dialogue in the College Setting." Race, Ethnicity and Education, 2004a, 7(3), 229-250.

Khuri, M. "Working with Emotion in Educational Intergroup Dialogue." International Journal of Intercultural Relations, 2004b, 28, 595-612.

Lane, K., Banaji, M., Nosek, B., and Greenwald, A. "Understanding and Using the Implicit Association Test: IV. What We Know (So Far) About the Method." In B. Wittenbrink and N. Schwarz (eds.), Implicit Measure of Attitudes. New York: Guilford Press, 2007. 
LeBaron, M., and Carstarphen, N. "Negotiating Intractable Conflict: The Common Ground Dialogue Process and Abortion." Negotiation Journal, 1997, 13(4), 341-361.

Levine, P., Fung, A., and Gastil, J. "Future Directions for Public Deliberation." Journal of Public Deliberation, 2005, 1(1), 1013.

Lowry, C., and Littlejohn, S. "Dialogue and the Discourse of Peace building in Maluku, Indonesia." Conflict Resolution Quarterly, 2006, 409-426.

Maiese, M. "Engaging the Emotions in Conflict Intervention." Conflict Resolution Quarterly, 2006, 24(2), 187-195.

Mansbridge, J., Hartz-Karp, J., Amengual, M., and Gastil, J. "Norms of Deliberation: An Inductive Study." Journal of Public Deliberation, 2006, 2(1), Article 7. Available from http://services.bepress.com/jpd/vol2/iss1/art7.

Maoz, I. "Participation, Control, and Dominance in Communication Between Groups in Conflict: Analysis of Dialogues Between Jews and Palestinians in Israel." Social Justice Research, 2001, 14(2), 189-208.

Masser, B., and Moffat, K. "'With Friends Like These ...' The Role of Prejudice and Situational Norms on Discriminatory Helping Behavior." Journal of Homosexuality, 2006, 51(2), 121-138.

McCoy, M., and McCormick, M. "Engaging the Whole Community in Dialogue and Action: Study Circles Resource Center." In D. Schoem and S. Hurtado (eds.), Intergroup Dialogue: Deliberative Democracy in School, College, Community and Workplace. Ann Arbor: University of Michigan Press, 2001.

Miller, J., and Donner, S. "More Than Just Talk: The Use of Racial Dialogues to Combat Racism.” Social Work with Groups, 2000, 23(1), 31-53.

Moradi, B., van den Berg, J., and Epting, F. "Intrapersonal and Interpersonal Manifestations of Antilesbian and Gay Prejudice: An Application of Personal Construct Theory." Journal of Counseling Psychology, 2006, 53(1), 57-66.

Munyandamusta, N., Mugiraneza, J.-P., and Van Brabant, K. "Rwanda Case Study Draft 3." 2005. Available from http://www.democraticdialoguenetwork.org/ documents/view.pl?s $=1 ;$ ss $=5 ; \mathrm{t}=; \mathrm{f} \_\mathrm{id}=11$.

Nagda, B. "Breaking Barriers, Crossing Borders, Building Bridges: Communication Processes in Intergroup Dialogue." Journal of Social Issues, 2006, 62(3), 553-576.

Nagda, B., and Derr, A. "Intergroup Dialogue: Embracing Difference and Conflict, Engendering Community." In W. Stephan and W. Paul Vogt (eds.), Education Programs for Improving Intergroup Relations. New York: Teachers College Press, 2004.

Nagda, B., Gurin, P., and Zuniga, X. (2008). "A Multi-University Evaluation of the Educational Effects of Intergroup Dialogue." Retrieved Feb. 23, 2008 from http://depts.washington.edu/sswweb/resweb/project.php?id=61.

Nagda, B., Kim, C.-W., and Truelove, Y. "Learning About Difference, Learning with Others, Learning to Transgress.” Journal of Social Issues, 2004, 60(1), 195-214.

Nagda, B., McCoy, M., and Barrett, M. "Mix It Up: Crossing Social Boundaries as a Pathway to Youth Civic Engagement." National Civic Review, 2006, 95(1), 47-56. 
Nagda, B. A., Spearmon, M., Holley, L. C., Harding, S., Balassone, M. L., MoiseSwanson, D., and De Mello, S. "Intergroup Dialogues: An Innovative Approach to Teaching About Diversity and Justice in Social Work Programs." Journal of Social Work Education, 1999, 35(3), 433-449.

Nagda, R., and Zuniga, X. "Fostering Meaningful Racial Engagement Through Intergroup Dialogues." Group Processes and Intergroup Relations, 2003, 6(1), 111-128.

National Coalition for Dialogue and Deliberation. "Engagement Excel File." 2007a. Available from http://www.thataway.org/exchange/files/docs/Engage ment_Streams.pdf.

National Coalition for Dialogue and Deliberation (2007b). Available from http://www.thataway.org/.National Coalition for Dialogue and Deliberation (2007c). http://www.thataway.org/?page_id=490\#dialogue.

National Issues Forums. (2006). Available from http://www.nifi.org/index.aspx.

Noto, G., Perlas, N., Hernandez, M., Diez Pinto, E., and Balcarbel, M. "Case Studies.” New York: United Nations Development Programme, 2004. Available from http://democraticdialoguenetwork.org/documents/view.pl?s=13; ss $=; \mathrm{t}=$;f_id $=225$.

Ohmer, M., and Korr, W. "The Effectiveness of Community Practice Interventions: A Review of the Literature." Research on Social Work Practice, 2006, 16, $132-145$.

Olson, M., and Fazio, R. "Reducing Automatically-Activated Racial Prejudice Through Implicit Evaluative Conditioning." Personality and Social Psychology Bulleting, 2006, 32, 421-433.

Ooms, T., Boggess, J., Menard, A., Myrick, M., Roberts, P., Tweedie, J., and Wilson, P. "Building Bridges Between Healthy Marriage, Responsible Fatherhood, and Domestic Violence Programs." Washington, D.C.: Center for Law and Social Policy, 2006. Available from http://www.clasp.org/publications/ building_bridges_guide.pdf.

Pan, D., and Mutchler, S. "Calling the Role: Study Circles for Better Schools: Policy Research Report." Study Circles. 2000. Available from http://www. studycircles.org/en/Resource.18.aspx.

Parrott, D., Zeichner, A., and Hoover, R. "Sexual Prejudice and Anger Network Activation: Mediating Role of Negative Affect." Aggressive Behavior, 2005, 32(1), 7-16.

Pettigrew, T. "Generalized Intergroup Contact Effects on Prejudice.” Personality and Social Psychology Bulletin, 1997, 23(2), 173-185.

Pettigrew, T. "Intergroup Contact Theory." Annual Review of Psychology, 1998, 49, 65-85.

Pettigrew, T., and Tropp, L. "A Meta-Analytic Test of Intergroup Contact Theory." Journal of Personality and Social Psychology, 2006, 90(5), 751-783.

Phinney, J., Ferguson, D., and Tate, J. "Intergroup Attitudes Among Ethnic Minority Adolescents: A Causal Model." Child Development, 1997, 68(5), 955-969. 
PNUD. "Building a Community of Practice." United Nations Development Programme, 2004a. Available from http://www.democraticdialoguenetwork.org/ documents/view.pl?s=3;ss=;t=;f_id $=269$.

PNUD. "Report on Activities." PowerPoint Presentation. United Nations Development Programme, 2004b. Available from http://www.democraticdialoguenetwork.org/documents.pl?s $=3$.

Price, V., and Capella, J. "Online Deliberation and its Influence: The Electronic Dialogue Project in Campaign 2000.” IT and Society, 2002, 1(1), 303-329.

Pruitt, B., and Kaufer, K. "Dialogue as a Tool for Peaceful Conflict Transformation. Working Paper Number 2." United Nations Development Programme, 2004. Available from http://www.democraticdialoguenetwork.org/documents .pl? $=2 ;$ ss $=11$.

Public Conversations Project. 2006. http://www.publicconversations.org/pcp/ index.php.

Public Dialogue Consortium. 2006. http://www.publicdialogue.org/.

Robinson, R., Keltner, D., Ward A., and Ross, L. "Actual Versus Assumed Differences in Construal: 'Naïve Realism' in Intergroup Perception and Conflict." Journal of Personality and Social Psychology, 1995, 68(3), 404-417.

Rodenborg, N., and Huynh, N. "On Overcoming Segregation: Social Work and Intergroup Dialogue." Social Work with Groups, 2006, 29(1), 27-44.

Rogers, R., Malancharuvil-Berkes, E., Mosley, M., Hui, D., and O'Garro-Joseph, G. "Critical Discourse Analysis in Education: A Review of the Literature." Review of Educational Research, 2005, 75(3), 365-416.

Ross, M. "Creating the Conditions for Peacemaking: Theories of Practice in Ethnic Conflict Resolution." Ethnic and Racial Studies, 2000, 23 (6), 1002-1034.

Rubin, A., and Babbie, E. Research Methods for Social Work. Belmont, Calif.: Thomson Learning, 2005.

Rudman, L, Ashmore, R., and Gary, M. "Unlearning' Automatic Biases: The Malleability of Implicit Prejudice and Stereotypes." Journal of Personality and Social Psychology, 2001, 81(5), 856-868.

Ryan, K., and DeStefano, L. (eds.). Evaluation as a Democratic Process: Promoting Inclusion, Dialogue and Deliberation. New Directions for Evaluation, no. 85. San Francisco: Jossey-Bass, 2000.

Saguy, T., Pratto, F. Dovidio, J., and Nadler, A. "Talking About Power: Group Power and the Desired Content of Intergroup Interactions." In S. Demoulin, J. Levens, and J. Dovidio (eds.), Intergroup Misunderstandings: Impact of Divergent Social Realities, in press.

Saunders, H. "Sustained Dialogue in Managing Intractable Conflict." Negotiation Journal, 2003, 19(1), 85-95.

Schoem, D. "Intergroup Dialogue for a Just and Diverse Democracy." Sociological Inquiry, 2003, 73(2), 212-227.

Schoem, D., and Hurtado, S. (eds.). Intergroup Dialogue: Deliberative Democracy in School, College, Community and Workplace. Ann Arbor: University of Michigan Press, 2001. 
Schutt, R. Investigating the Social World: The Process and Practice of Research. Thousand Oaks, Calif:: Sage, 2004.

Schutz, H., and Six, B. "How Strong Is the Relationship Between Prejudice and Discrimination? A Meta-Analytic Answer." International Journal of Intercultural Relations, 1996, 20(3/4), 441-462.

Search for Common Ground. 2006. http://www.sfcg.org/programmes/ilr/ programmes_ilr.html.

Slotte, S. "Systems Sensitive Dialogue Intervention." Systems Research and Behavioral Science, 2006, 23, 793-802.

Spears, I. "Understanding Inclusive Peace Agreements in Africa: The Problems of Sharing Power." Third World Quarterly, 2000, 21(1), 105-118.

Spencer, M. "Social Work 709: Training in Intergroup Dialogue Facilitation: Skills for Multicultural Social Work Practice." 2004. Available at http://www. ssw.umich.edu/shared/course_outlines/20052/ms709-001f04.pdf.

Staub, E. "Preventing Violence and Terrorism and Promoting Positive Relations Between Dutch and Muslim Communities in Amsterdam." Peace and Conflict: Journal of Peace Psychology, 2007, 13 (3), 333-360.

Steinberg, S. "Discourse Categories in Encounters Between Palestinians and Israelis." International Journal of Politics, Culture and Society, 2004, 17(3), 471-489.

Stephan, W. "Evaluation of Dialogue Programs." 2006. Available from http://www-psych.nmsu.edu/faculty/wstephan.html.

Stephan, W., and Finlay, K. "The Role of Empathy in Improving Intergroup Relations." Journal of Social Issues, 1999, 55(4), 729-743.

Stephan, C., Renfro, L., and Stephan, W. "The Evaluation of Multicultural Education Programs: Techniques and a Meta-Analysis." In W. Stephan and W. Paul Vogt (eds.), Education Programs for Improving Intergroup Relations: Theory, Research and Practice. New York: Teachers College Press, 2004.

Stephan, W., and Stephan, C. "Intergroup Anxiety.” Journal of Social Issues, 1985, 41, 157-175.

Stephan, W., and Stephan, C. "Predicting Prejudice." International Journal of Intercultural Relationships, 1996, 20(3/4), 409-426.

Stephan, W., and Stephan, C. Improving Intergroup Relations. Thousand Oaks, Calif.: Sage, 2001.

Stephan, W., Ybarra, O., and Bachman, G. "Prejudice Towards Immigrants: An Integrated Threat Theory." Journal of Applied Social Psychology, 1999, 29, 2221-2237.

Stephan, W., Ybarra, O., Martinez, C., Schwarzwald, J., and Tur-Kaspa, M. "Prejudice Toward Immigrants to Spain and Israel: An Integrated Threat Theory Analysis." Journal of Cross-Cultural Psychology, 1998, 29(4), 559.

Study Circles Resource Center. 2006. http://www.studycircles.org/en/index.aspx. Suleiman, R. "Planned Encounters Between Jewish and Palestinian Israelis: A Social-Psychological Perspective." Journal of Social Issues, 2004, 60(2), 323-337.

Thillet de Solorzano, B. "Democracy and Dialogues: Challenges for Democracy in the XXI Century." New York: United Nations Development Programme, 
2004. Available from http://democraticdialoguenetwork.org/documents/view. pl?s=13;ss=;t=;f_id $=217$.

Thompson-Robinson, M., Hopson, R., and SenGupta, S. (eds.). In Search of Cultural Competence in Evaluation: Towards Principles and Practices. New Directions for Evaluation, no. 102. San Francisco: Jossey-Bass, 2004.

Trevino, J. "Voices of Discovery: Intergroup Dialogues at Arizona State University." In D. Schoem and S. Hurtado (eds.), Intergroup Dialogue: Deliberative Democracy in School, College, Community and Workplace. Ann Arbor: University of Michigan Press, 2001.

United Nations Development Programme (UNDP). "Documents on Dialogue." Retrieved Feb. 23, 2008 from http://www.democraticdialoguenetwork.org/ documents.pl? $=2 ;$ ss $=11$.

Volkan, V. "The Tree Model: Psychopolitical Dialogues and the Promotion of Coexistence." In E. Weiner (ed.), The Handbook of Interethnic Coexistence. New York: Continuum, 1998.

Weiner, E. (ed.), The Handbook of Interethnic Coexistence. New York: Continuum, 1998.

Western Justice Center Foundation. 2006. Available from http://www.western justice.org/.

Wittenbrink, B., Judd, C., and Park, B. "Evidence for Racial Prejudice at the Implicit Level and Its Relationship with Questionnaire Measures." Journal of Personality and Social Psychology, 1997, 72(2), 262-274.

World Café. 2006. http://www.theworldcafe.com/.

WSP/UNDP-DRLAC. "Permanent Evaluation of Conflict Resolution Interventions: Proposal." Latin American Office, 2003. Available from http:// www.democraticdialoguenetwork.org/documents.pl?s $=2 ; s s=11$.

WSP/UNDP-DRLAC. "Permanent Evaluation of Conflict Resolution Interventions: A Proposal." Latin American Office, 2003. Available from http://www. democraticdialoguenetwork.org/documents.pl?s $=2 ; s s=11$.

Zappen, J. "Bakhtin's Socrates." Rhetoric Review, 1996, 15, 66-83.

Zuniga, X., Nagda, B., Chesler, M., and Cytron-Walker, A. "Intergroup Dialogue in Higher Education: Meaningful Learning About Social Justice." ASHE Higher Education Report, 2007, 32(4).

Adrienne Dessel teaches in the University of Michigan's Program on Intergroup Relations, focusing on intergroup dialogue and conflict resolution, with particular attention paid to social identity, oppression, privilege, and social justice education.

Mary E. Rogge is an associate professor at the University of Tennessee College of Social Work and is currently principle investigator of a four-year National Institute of Environmental Health Science Environmental Justice grant (http://chattanoogacreek.utk.edu). 